\title{
تأثير خبرة المدقق على جودة التدقيق الداخلي
}

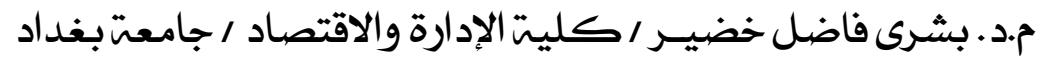
م.م. عمار لؤي عبد الرزاق

تاريخ التقايم:2017/1/3

تاريخ القبول:2017/3/23

تتجلى أهمية التدقيق الداخلي في الطلب المتزايد على خلماته في الوحدات الاقتصادية العامـة والخاصـة،

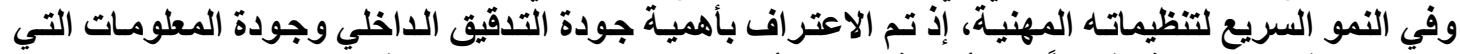

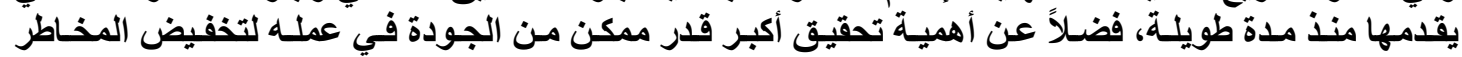

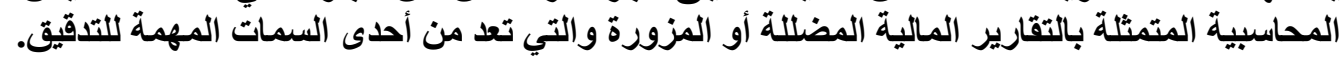

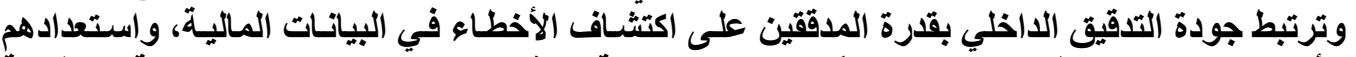

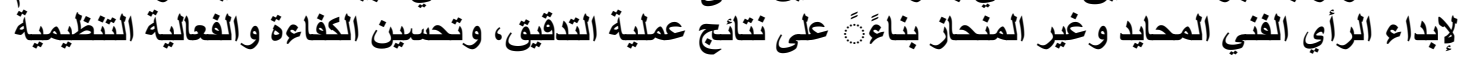

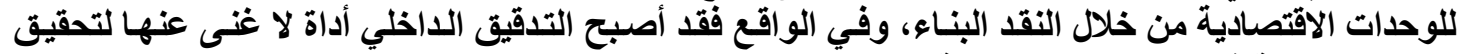
السيطرة الفعالة في الوحدات الاقتصادية منادية.

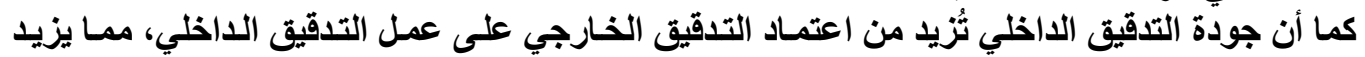
من كفاءة التدقيق الخارجي ويقلل أعبائه.

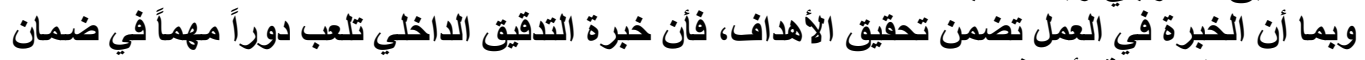

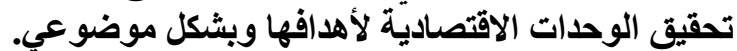

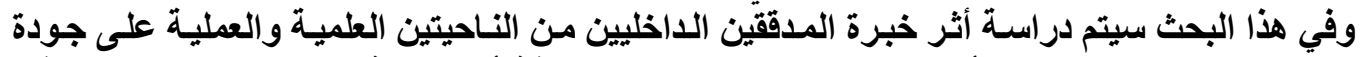

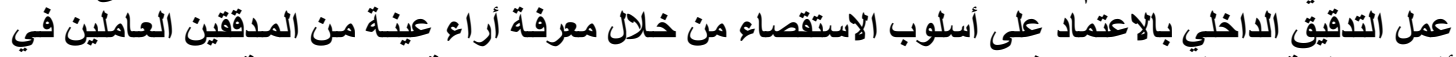

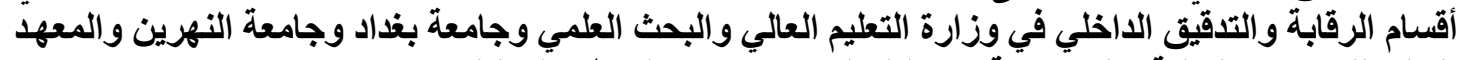

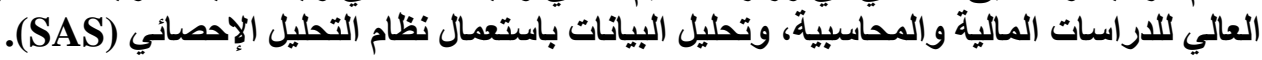
الإسطات الرئيسة للبحث: المدقق، خبرة المدقق، التدقيق الداخلي، جودة التدقيق الداخلي.

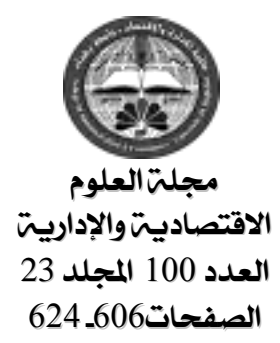




\section{تأثير خبرة المدقق على جورة التدقيقا الداخليا}

\section{الحهور الأول/ هنهجية البحث ودراسات سسابقة}

1- هشكائة البمث: يسعى البحث إلى الإجابة عن التساؤلات الآتية:

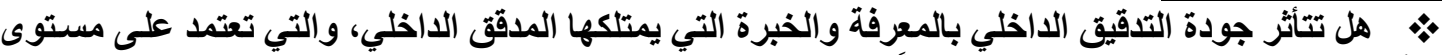

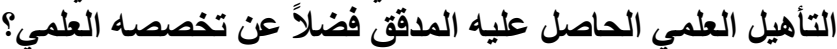

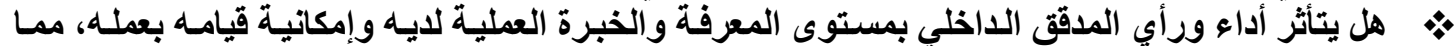

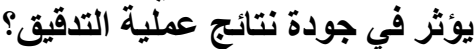

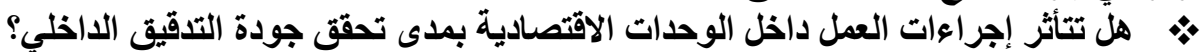
2- أهمية البحث: تنبع أهمية البحث من أهمية مهنة التدقيق الداخلي، وزيادة الاعتمـاد على أراء المدققين

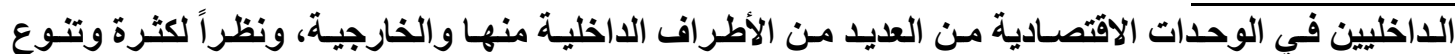

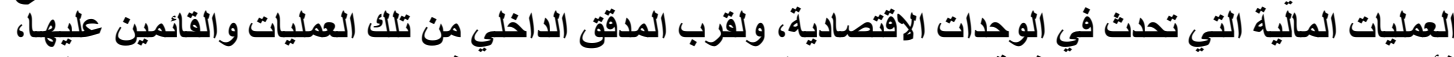

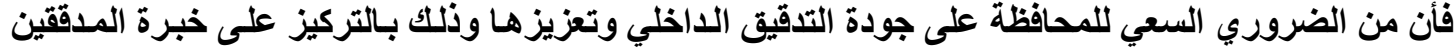
ودورهم في تحقيق تلك الجودة.

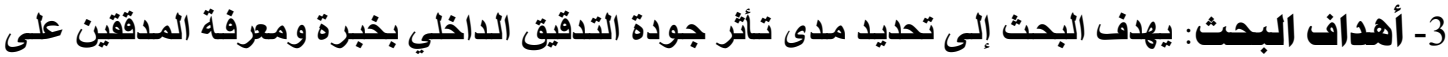

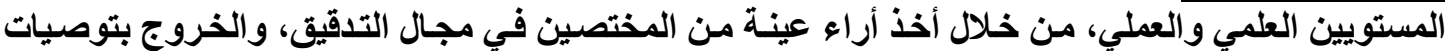
تساعد على الارتقاء بواقع العمل التدقيقي وتعمل على تعزيز جودة التدقيق.

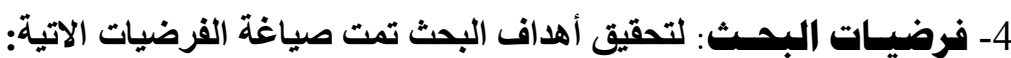

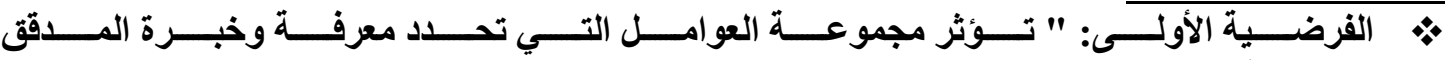
على جودة التدقيق الداخلي". • مالفرضية الثانية: " تؤثر مجموعة العو امل التي تتعلق بخبرة ومعرفة المدققين وإمكانية قيامهم بعملهم على جودة التّقيق الداخلي ". مث الفرضية الثالثة: " تتأثر إجراءات العمل داخل الوحدة الاقتصادية بمدى تحقق جودة التدقيق الداخلي ".

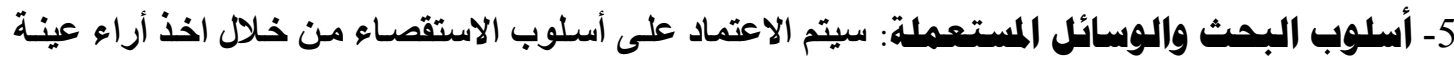

من المدققين الأخليين، وتحليل البيانات باستعمال نظام التحليل الإحصائي (SAS).

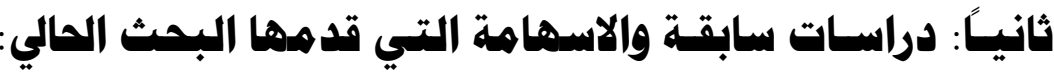

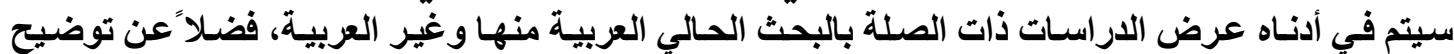

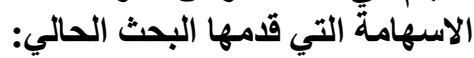
1 1راسات ستابقة: دراسة منشورة في مجلة كلية الإدارة والاقتصاد / جامعة البصرة بعنوان " العوامل المؤثرة في جودة العملية

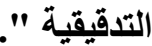
هدفت الدراسة إلى تحديد العوامل المؤثرة في تحقيق الجودة في العملية التدقيقية، وقد صنفت هذه العية العوامل إلى العي

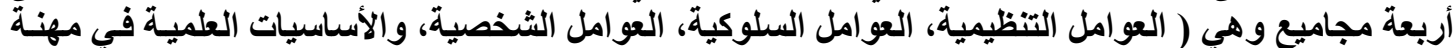
التدقيق )، وقد توصلت الاراسة إلى أن لكل مجموعة من العوامل لها لهاتثير هـا في تحقيق الجودة في العملية 


\section{تأثير خبرة المدقق على جورة التدقيقا الداخليا}

: Curtis \& et. al., 2009 ) خ مراسة " Auditors' Training \& Proficiency in Information Systems: A Research Synthesis ".

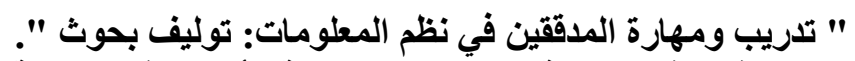

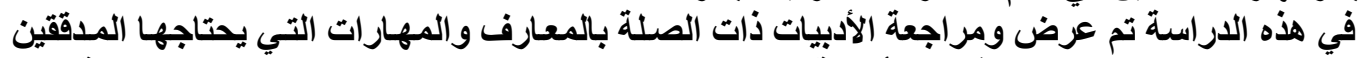

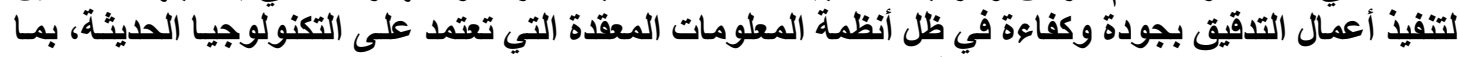

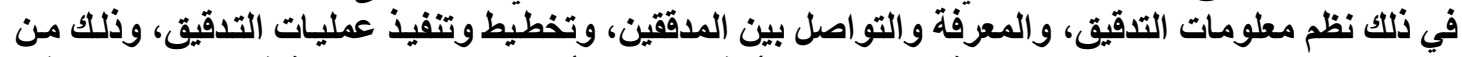

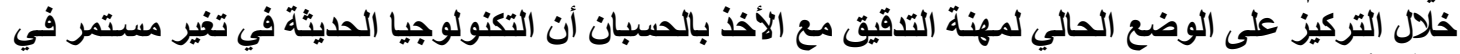

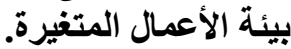

وأثارت الاراسة إلى صعوبة تكيف بعض معايير التدقيق مع التكنولوجيا الحالية التي من المرجح أنها

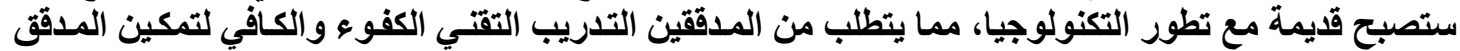
من الالتزام بمعايير التدقيق.

"Internal Audit Quality: A Multi-Stakeholder Analysis".

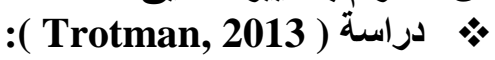
" جودة التدقيق الداخلي: تحليل أصحاب المصالح المتعددين ".

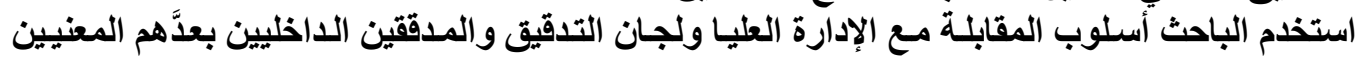

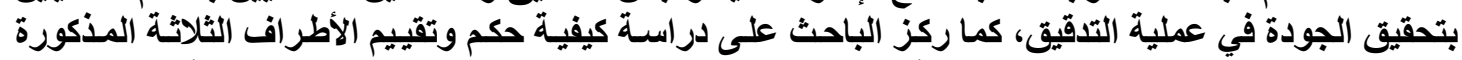

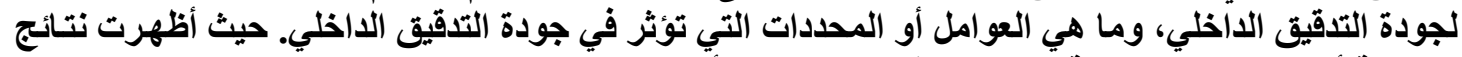

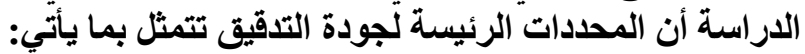

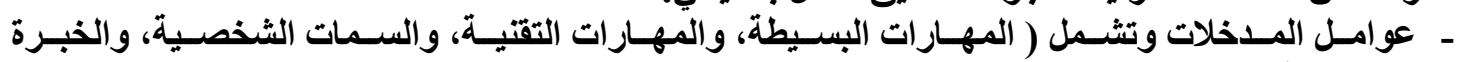
و الموضوعية ). ـ ـ العمليات وتثثمل ( العلاقات القوية،، ونهج التدقيق المتبع، والتدقيق مع فهم الأعمال ).

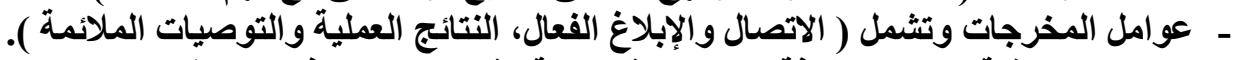

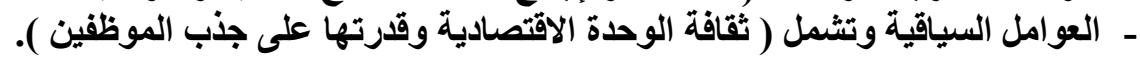

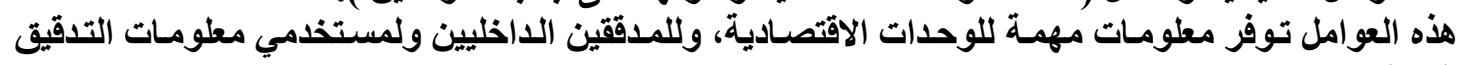
كما قاخمت هذه الأدراسة فهم أكثر شمولية لجودة التدقيق الداخلي من خلال دمبج أراء الإدارة والمدققين، وقام

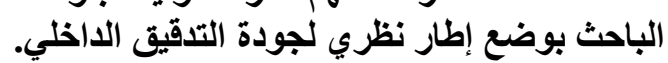

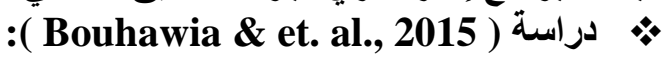

" The Effect of Working Experience, Integrity, Competence, and Organizational Commitment on Audit Quality: Survey State Owned Companies In Libya ".

" تأثير الخبرة في العمل، والنزاهـة، والكفاعة والالتزام التنظيسي على جودة التدقيق: مسـح للثركات الليبية

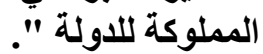

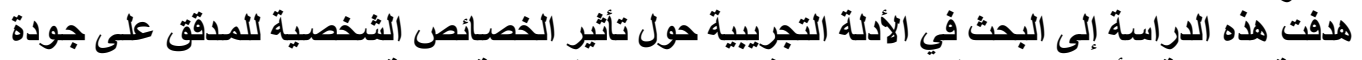

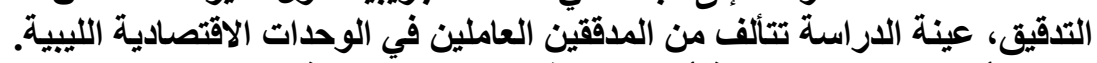

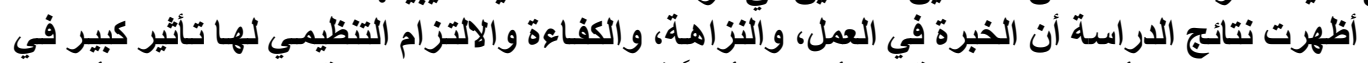

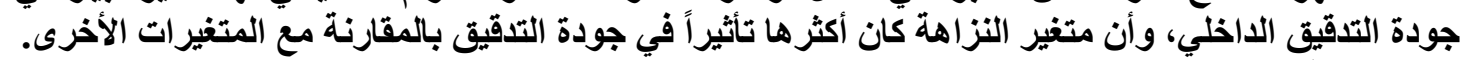

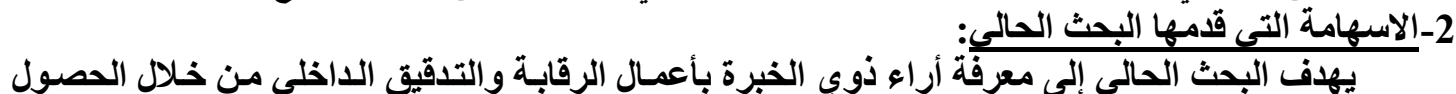

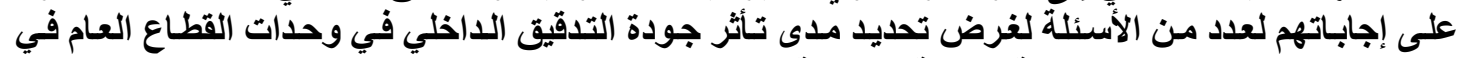
العراق بخبرة المدققين من الناحية العلمية والعملية. 


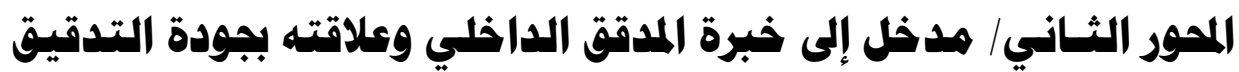

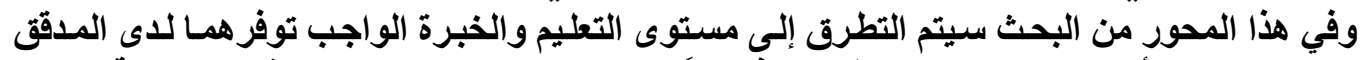

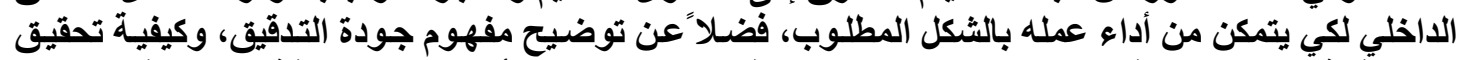

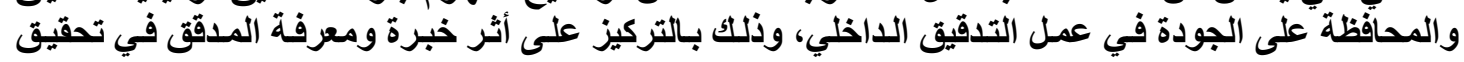
وتعزيز تلك الجودة.

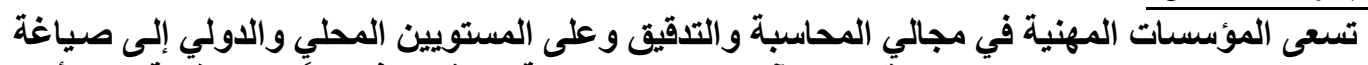

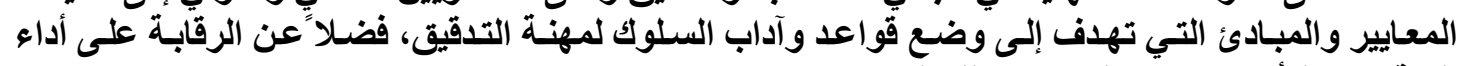

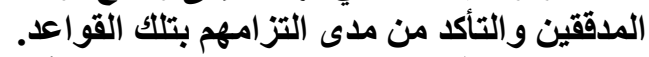

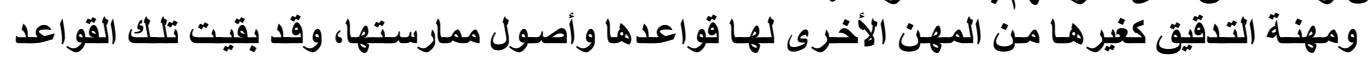

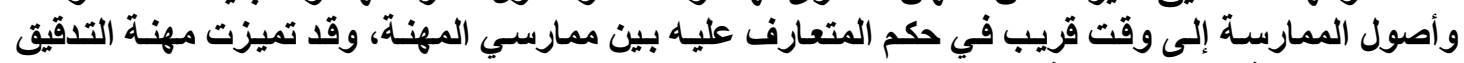

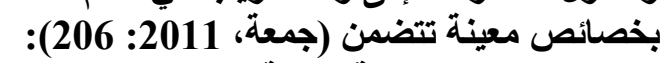

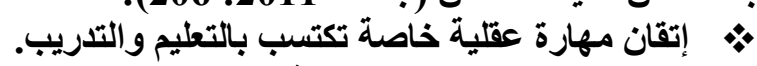

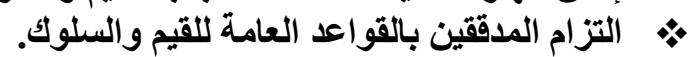

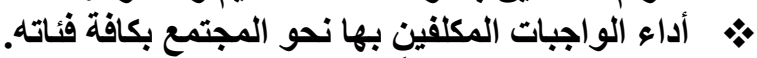

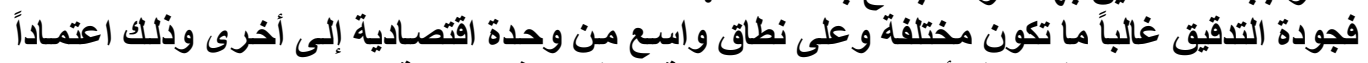

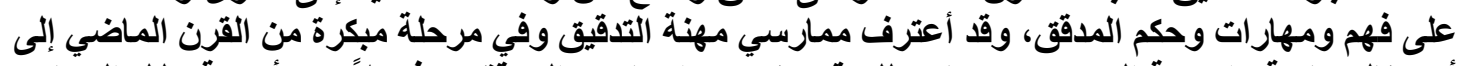

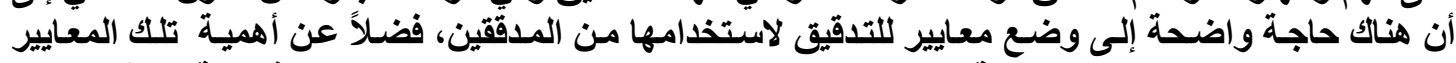

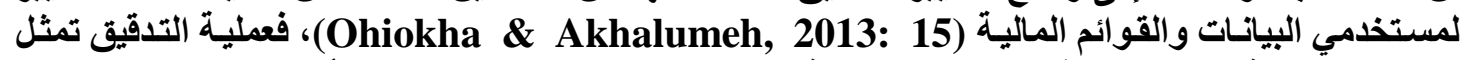

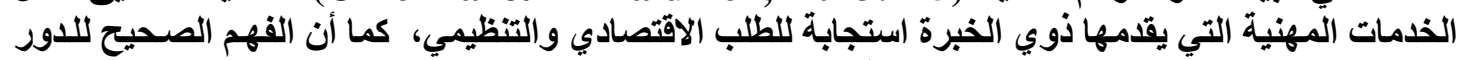

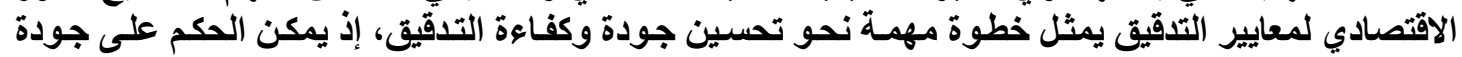

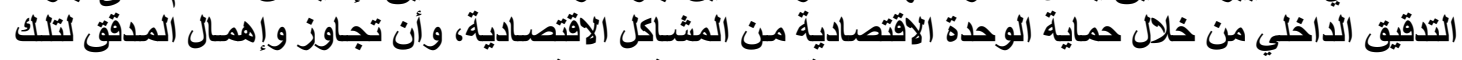

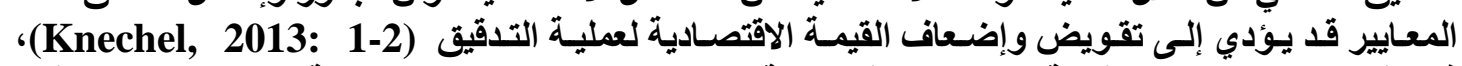

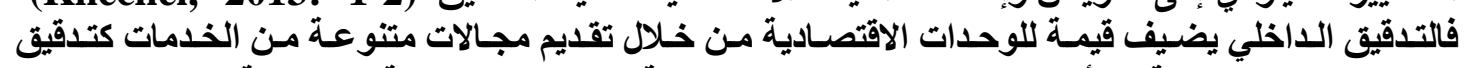

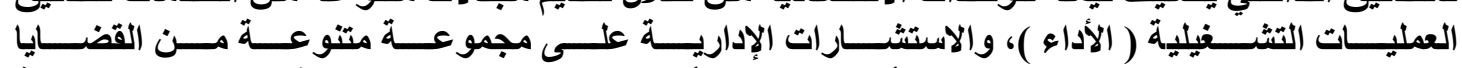

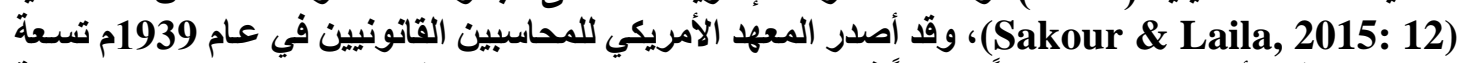

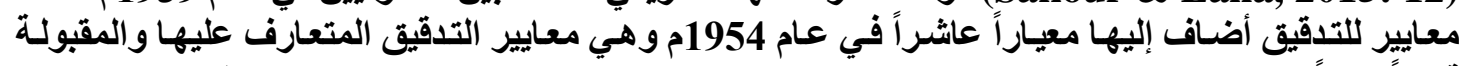

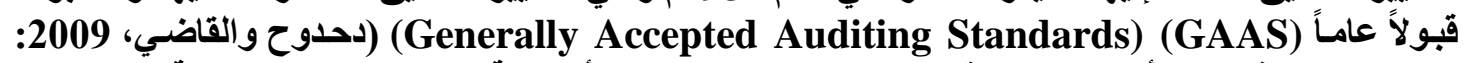

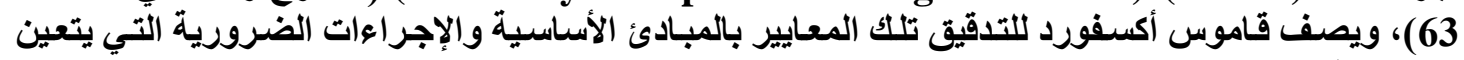

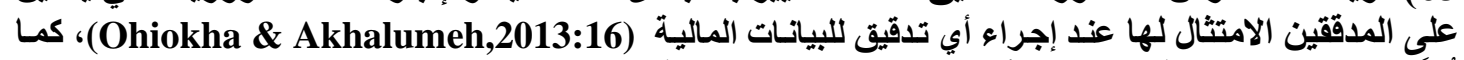

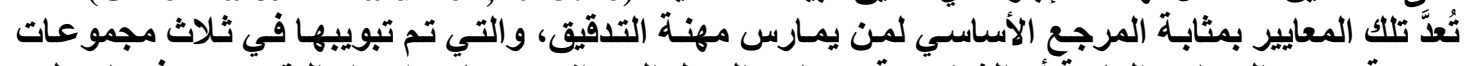

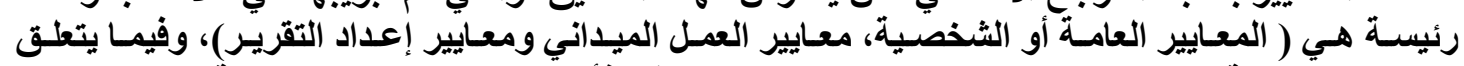

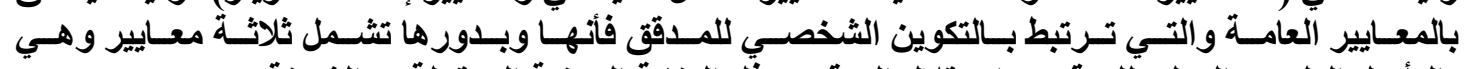

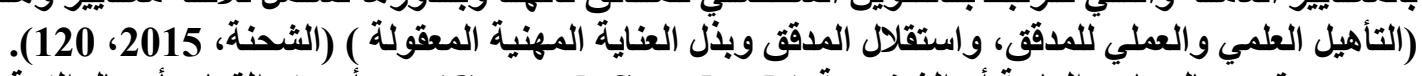

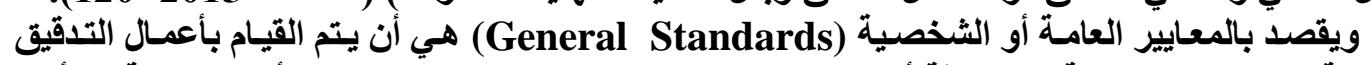

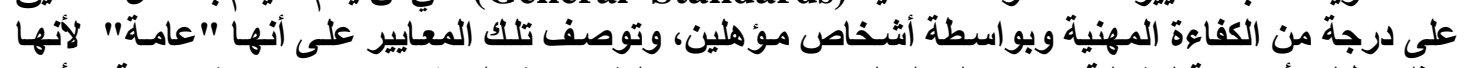

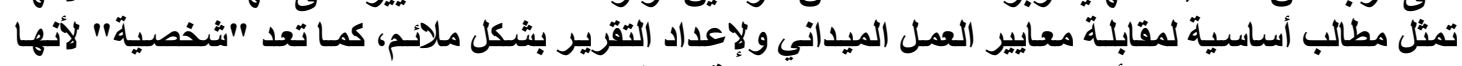

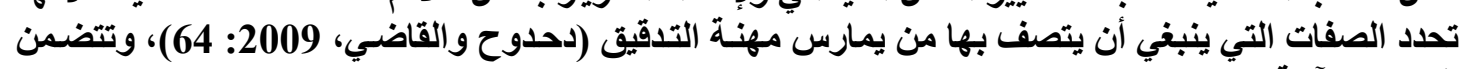

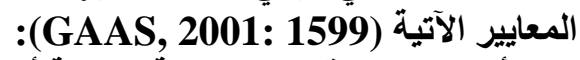

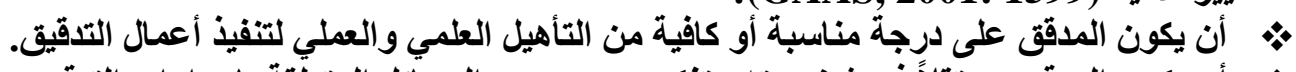

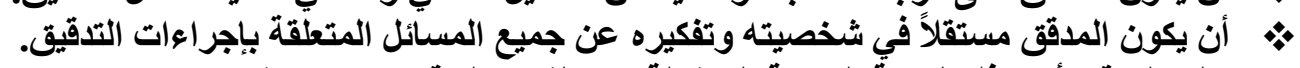

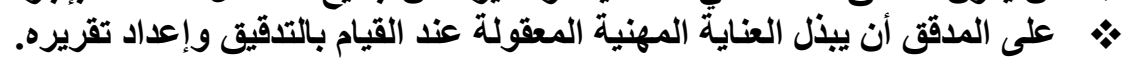




\section{تأثير خبرة المدقق ملى جودة التدقيقا الداخليا}

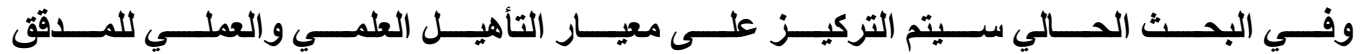
(Scientific \& Practical Qualification for Auditor)

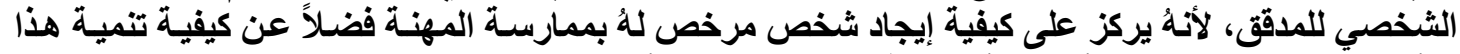

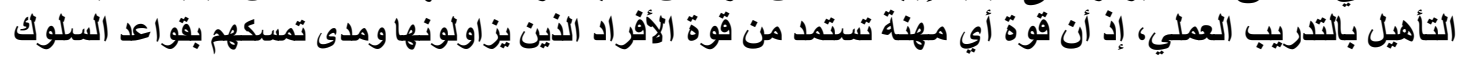

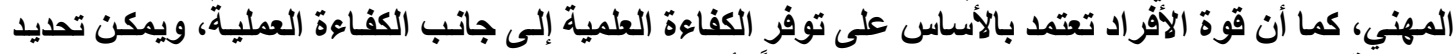

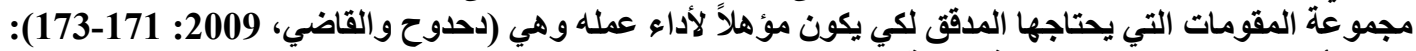

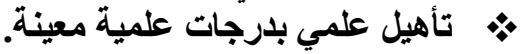

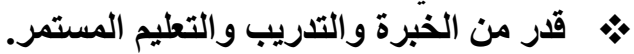

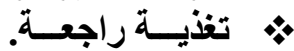

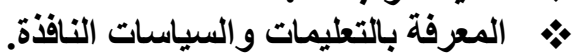

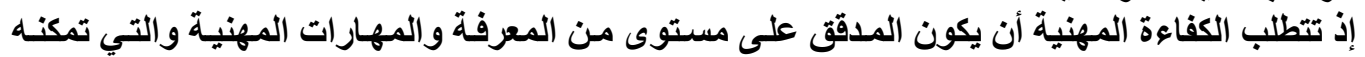

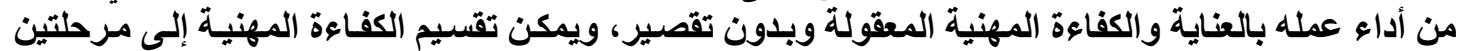

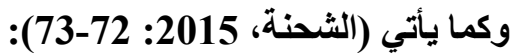

الأولى: تثمثل باختيار الكفاءات المهنية ذات الخئية الخبرة والمعرفة والتأهيل الكافي لأداء أعمال التدقيق.

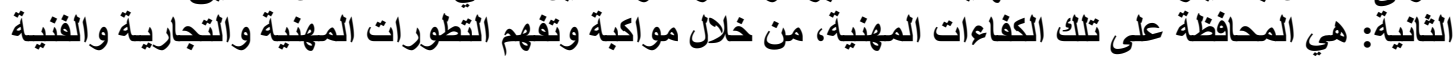

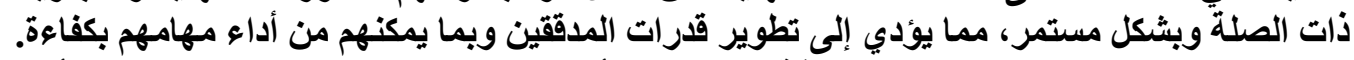

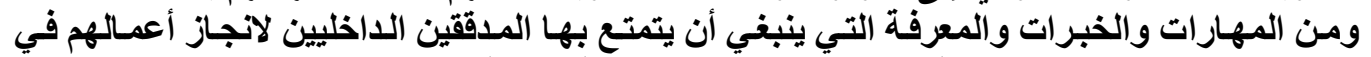

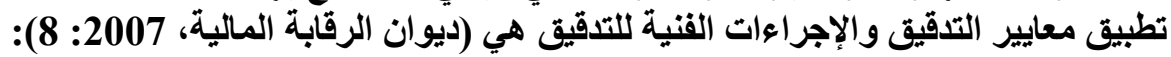

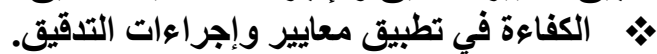

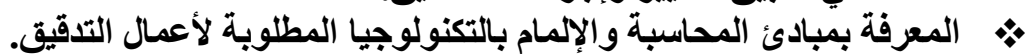

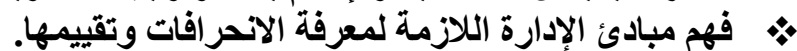

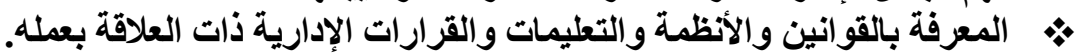

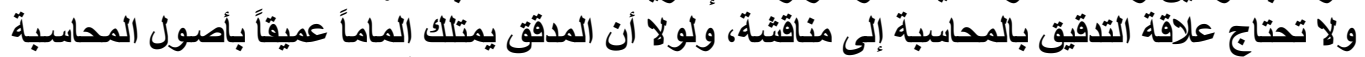

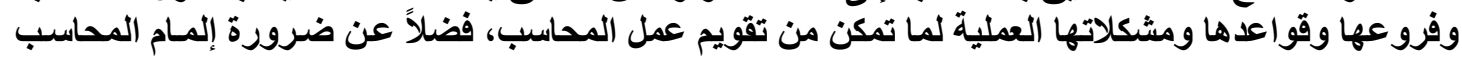

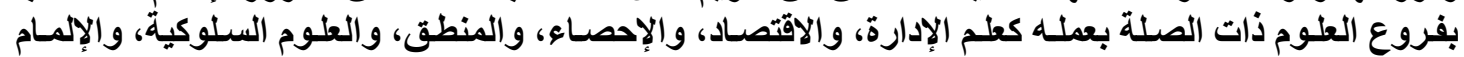

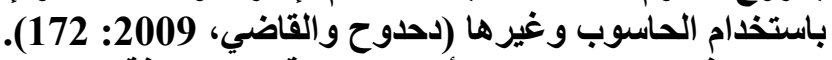

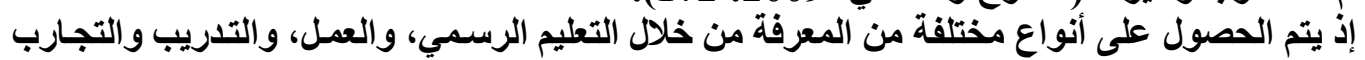

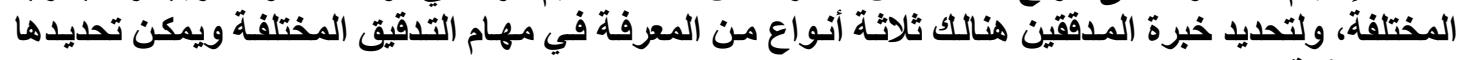
بالنقاط الآتية (Bonner \& Lewis, 1990:4-6)

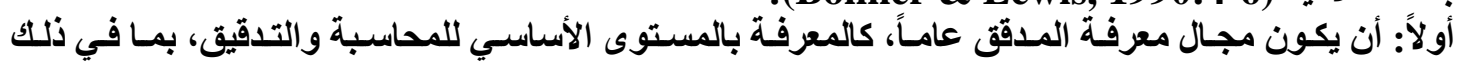

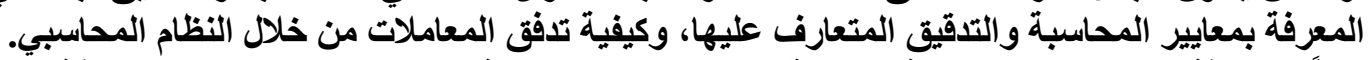

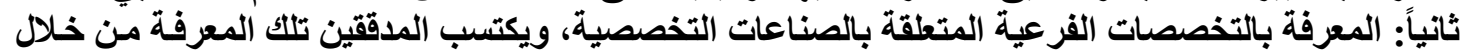

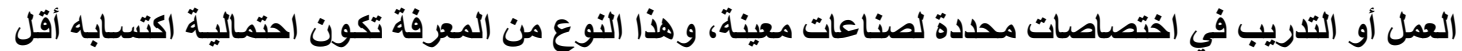

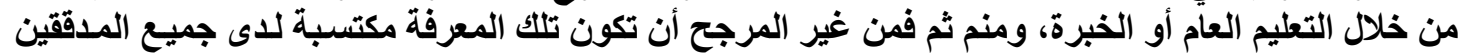

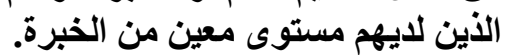

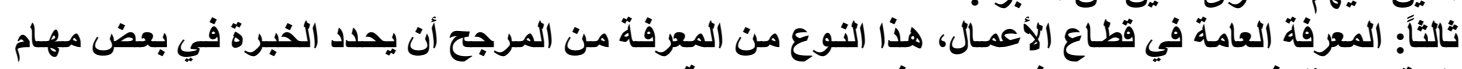

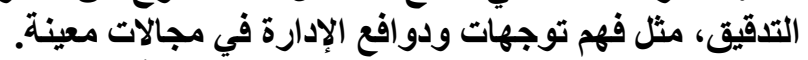

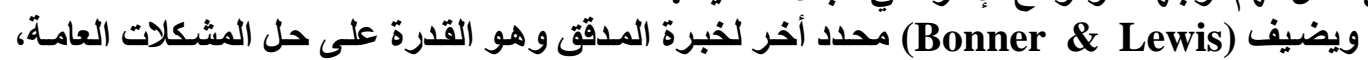

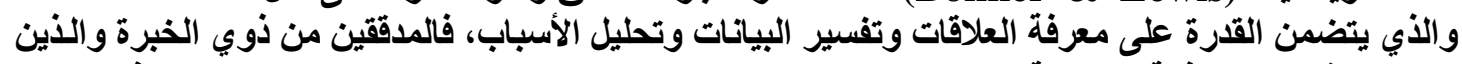

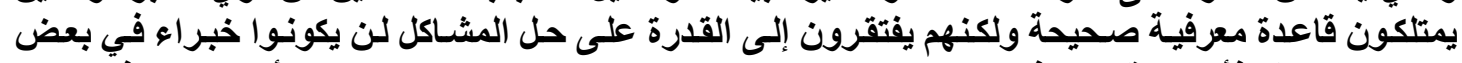

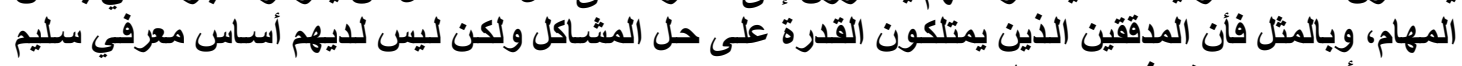

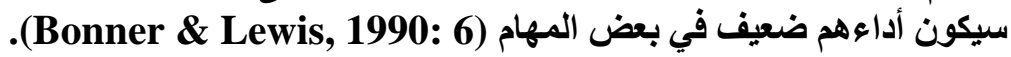




\section{تأثير خبرة المدققا على جورة التوقيقا الداخليا}

فالخبرة والقدرة تؤثران بثكل كبير على المعرفة، كمـا أن القدرة والمعرفة بدورهما يؤثران على أداء

المدقق بشكل مباشر، وكما هو مبين في الثكل الآتي (Berberich, 2005: 163):

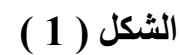

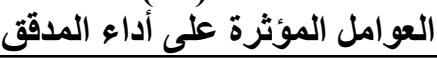

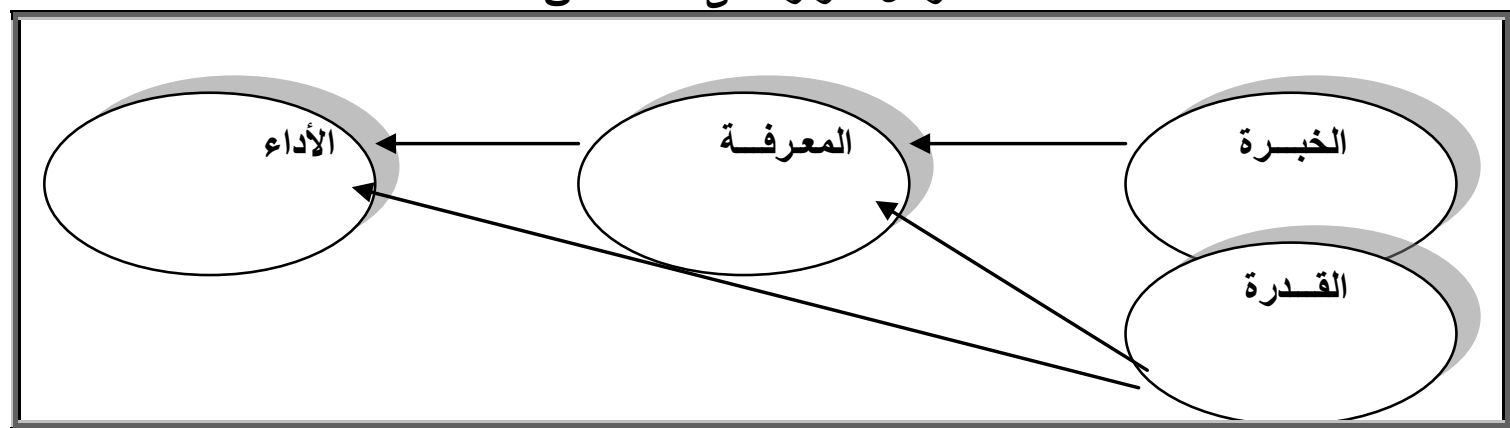

Source:(Berberich, 2005: 163).

ويرى الباحثان في أن مفهوم القدرة قائم على أسـاس الفطرة، ويعتمد على قابليـة و إمكانيـة المدقيق

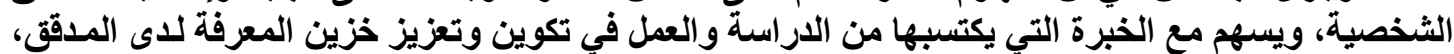

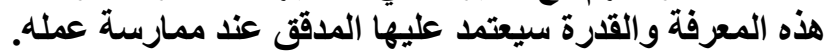

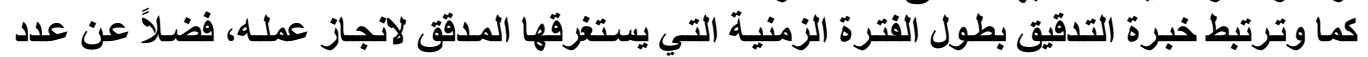

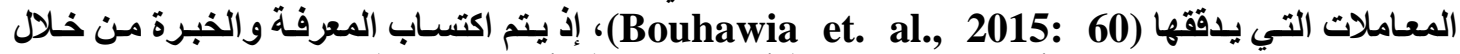

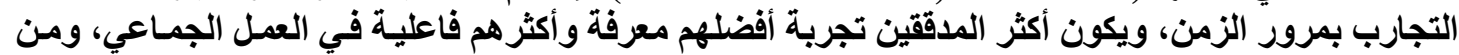

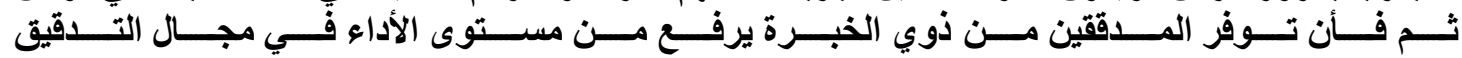

(Abdullah, 2014: 55)

والجدول الآتـي يبين العنـاوين الوظيفيـة لمـوظفي أقسـام الرقابـة والتـقيق الـاخلي والحــ الأدنس مـن التعليم

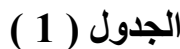

والخبرة المطلوبة للحصول على تلك العناوين:

العناوين الوظيفية للمدققين الداخليين،

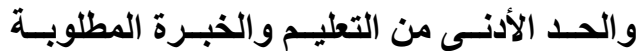

\begin{tabular}{|c|c|c|}
\hline التعليـــم والخبـرة & العنـــوان الوظيفــــ & $ت$ \\
\hline 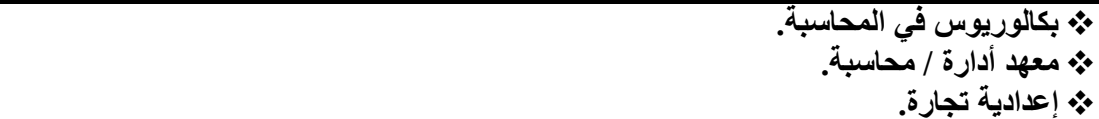 & كاتب تدقيق & .1 \\
\hline 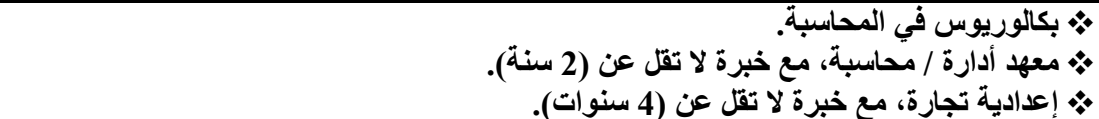 & معاون مدقق حسابات & .2 \\
\hline 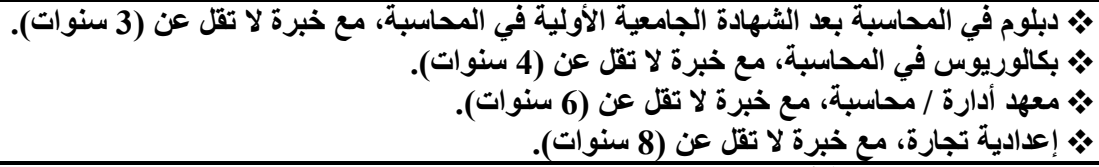 & مدقق حسابات & .3 \\
\hline 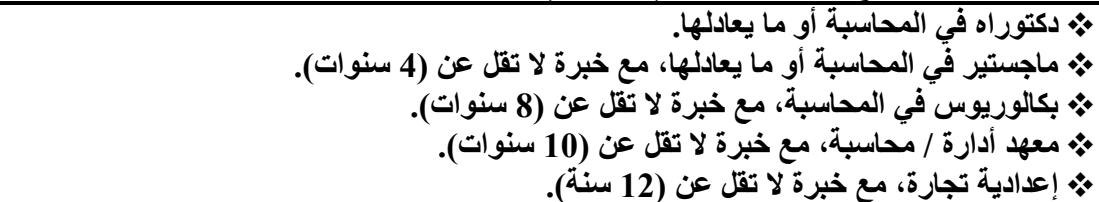 & مدقق حسابات أقدم & .4 \\
\hline
\end{tabular}


تأثير خبرة المدقة على جودة التدقيقا الداخليا

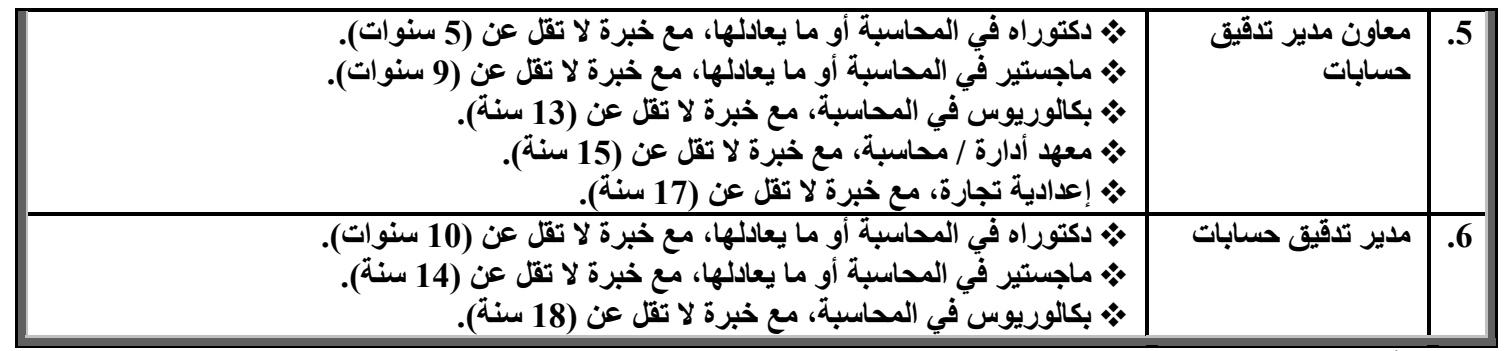

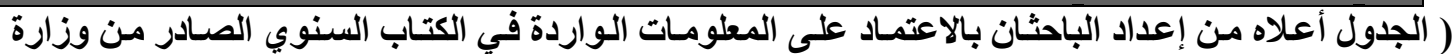

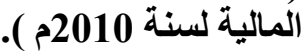

وتجدر الإشارة الى ان سنوات الخبرة الواردة في الجدول المذكور آنفاً تكون في مجال الاختصساص وبعد

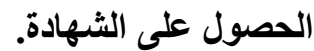

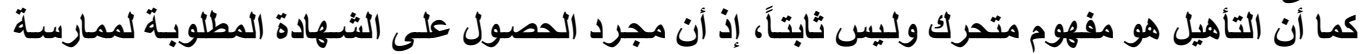

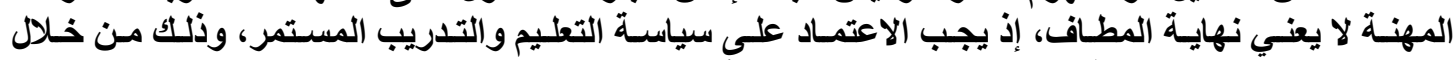

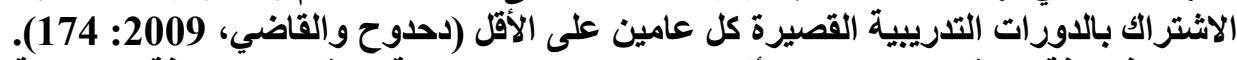

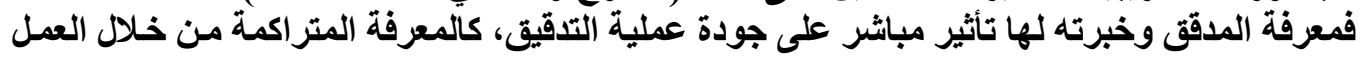

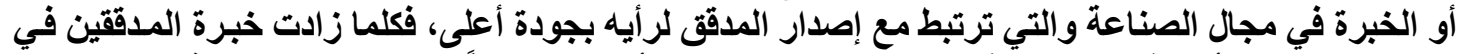

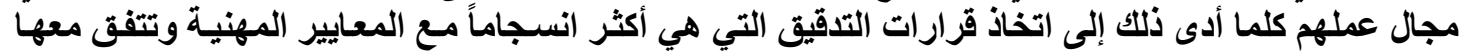

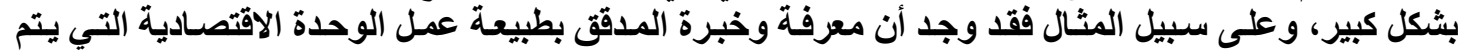

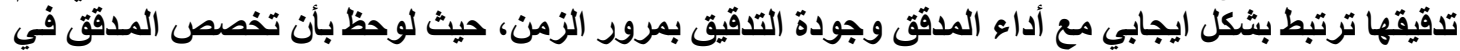

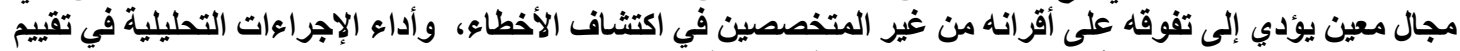
مخاطر التدقيق والكثف عن أوجه القصور في الرقابة الداخلية (Knechel, et. al., 2012: 11-12).

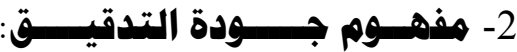

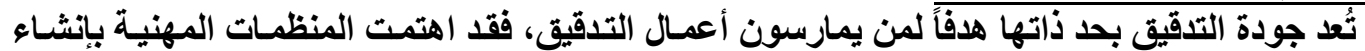

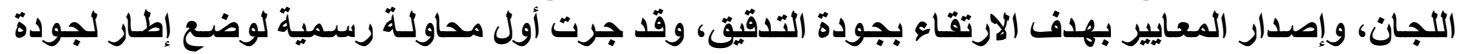

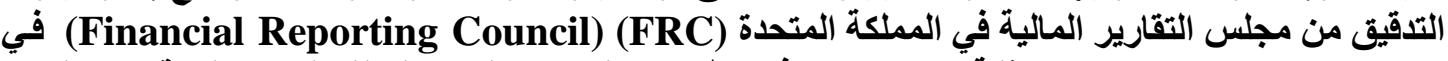

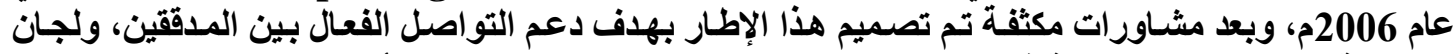

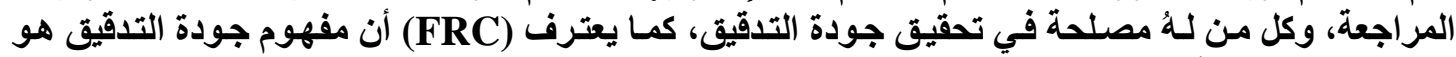

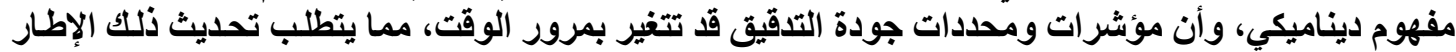
في ضوء ما قد يحدث من تغيران مؤنيرات (FRC, 2008: 1-2).

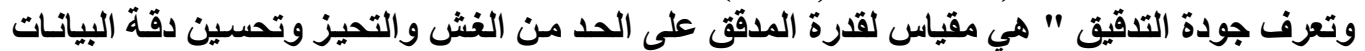

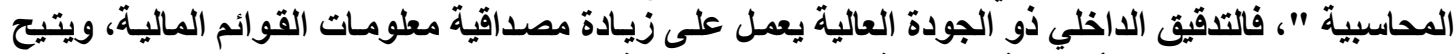

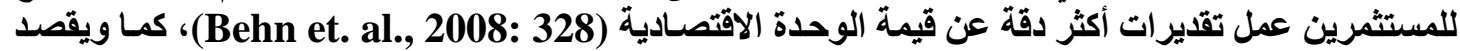

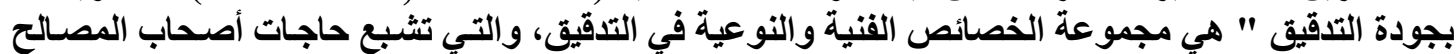

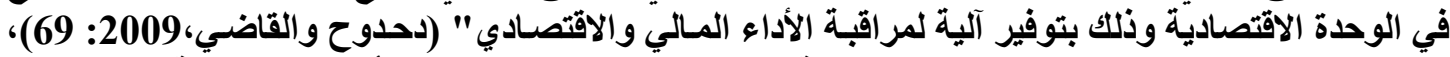

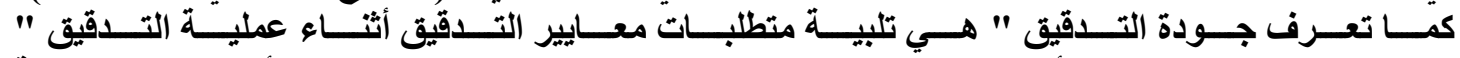

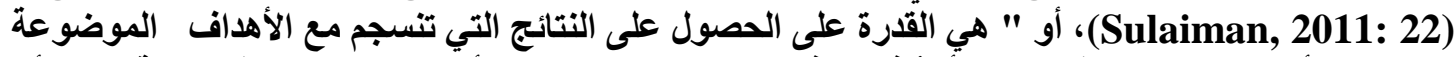

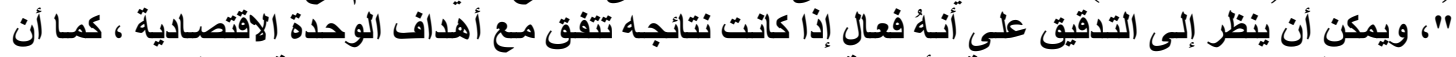

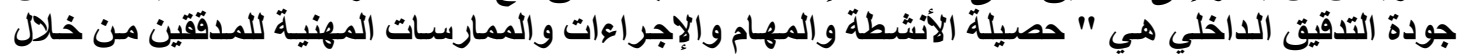

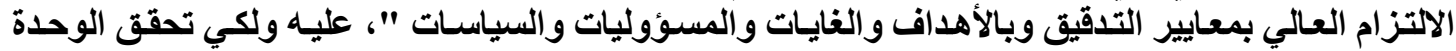

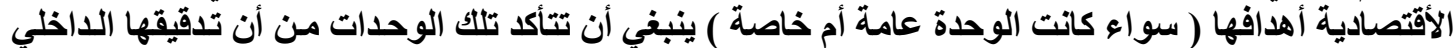

ذو جودة عالية (Badara \& Saidin, 2013: 341). 


\section{تأثير خبرة المدقق على جورة التدقيقا الداخليا}

وكذلك تعرف جودة التدقيق " هي إحتمـال إكتثـاف والإبـلاغ عن الأخطاء الجوهريـة و المعلومـات غير

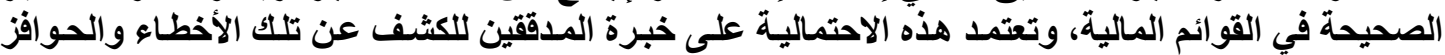

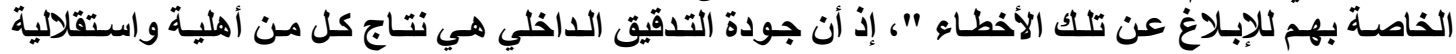

المدققين الاخليين (Benslimene \& Dumontier, 2014: 3-5). أما (Elshafie \& Nyodrah) فيشيران في دراستهما إلى أن مفهوم جودة التدقيق هو مفهوم معقد

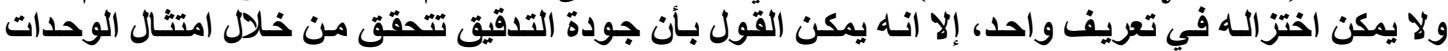

الاقتصادية لمبادئ المحاسبة المقبولة قبولاً عامياً (Elshafie \& Nyodrah, 2014: 43).

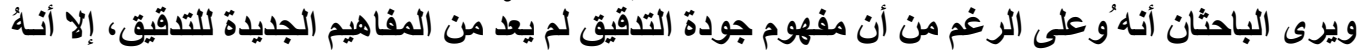

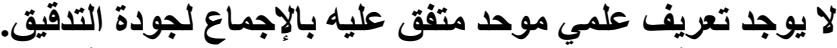

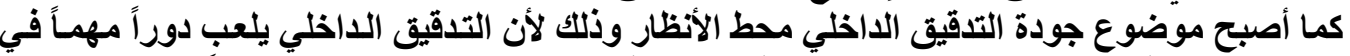

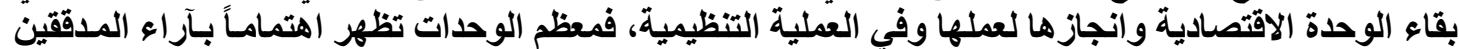

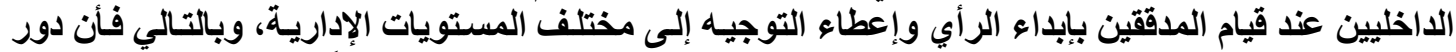

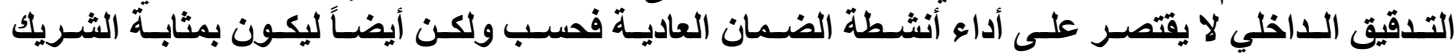

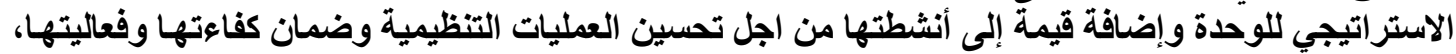

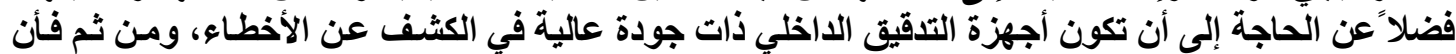

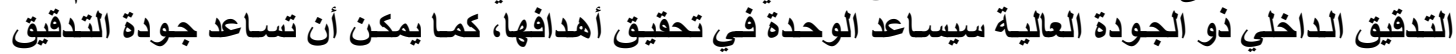

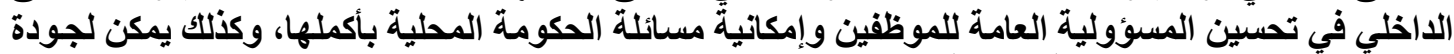
التدقيق الأخلي أن تكون عاملاً أساسياً في تحسين ثقة العامة بالتقارير المالية إذا كان التدقيق الداخلي يتضمن

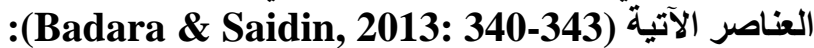

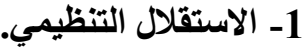

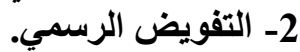

3- 3- معايير التدقيق المهنية. 4- إمكانية الحصول على المعلومات بشئ المكل غير مقيد.

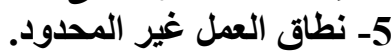

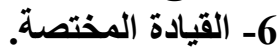

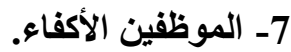

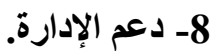

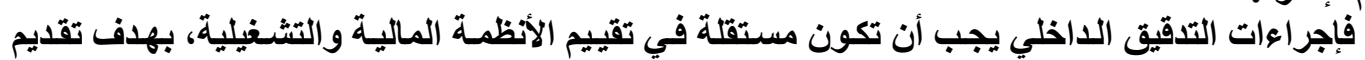

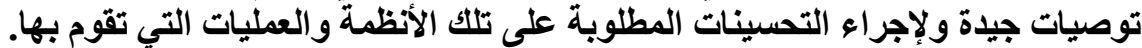

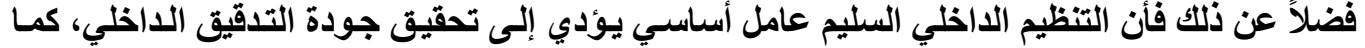

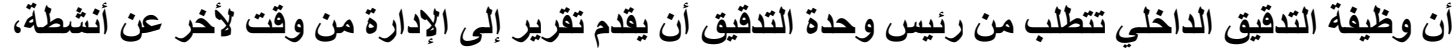

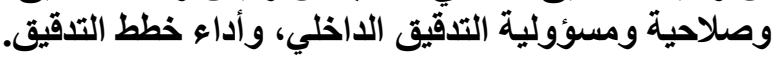

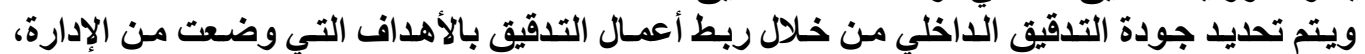

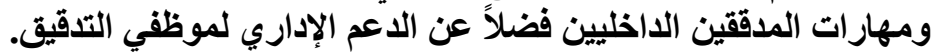

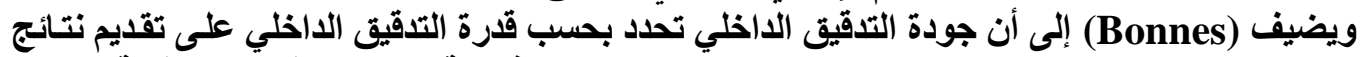

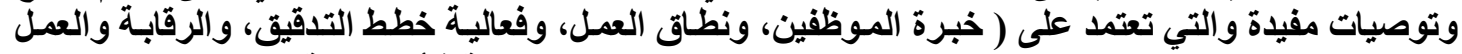

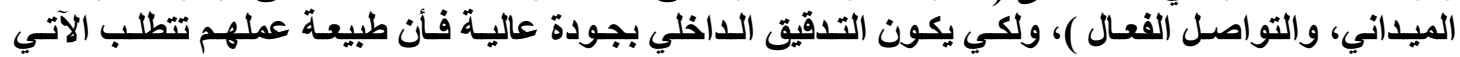
:(Bonnes, 2012: 30) • • المدققين الداخليين لا يمكن أن يؤدوا عملهم كمستشارين للإدارة العليا، لأن ذلك يتعارض مع قدرتهم على تقليم التقييمات المستقلة. • يجب على موظفي التدقيق الداخلي اكتسـاب مهارات العمل في مجموعة متنوعة من المجالات أبعد من

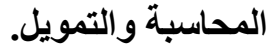




\section{تأثير خبرة المدقق على جورة التدقيقا الداخليا}

كما إن زيادة الاعتماد على التدقيق الاخلى تزيد من ضرورة أن تكون المعلومـات التي يقدمها مفهومـة

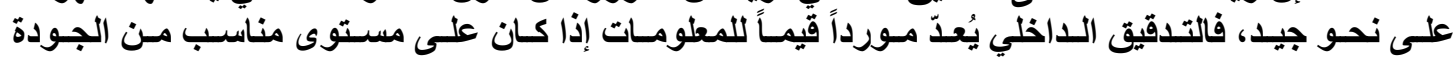

.(Trotman, 2013: 3)

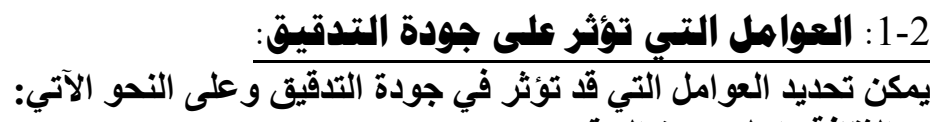

$$
\begin{aligned}
& \text { 1 1-الثقافة داخل وحدة التدقيق. } \\
& \text { 2-المهارات و الصفات الثخصية للمدققين. } \\
& \text { 3-فاعلية عملية التدقيق. } \\
& \text { 4-الملاءمة واعلية والمصداقية فئية تقارير التدقيق. }
\end{aligned}
$$

5- عوامل خارجية قد تؤثر في جودة التدقيق (FRC, 2008: 1)

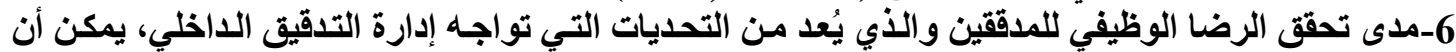

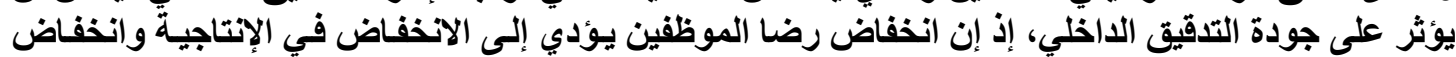

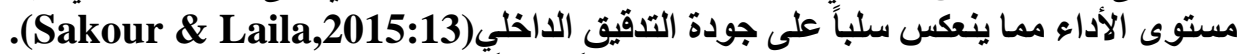

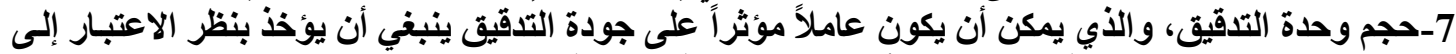

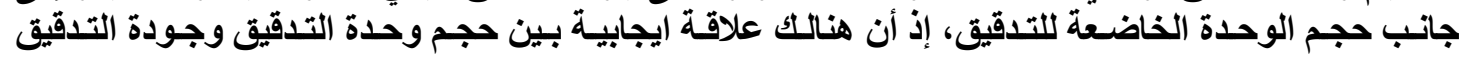

.(Aamir \& Farooq,2011:9)

8-إن عملية التدقيق هي للحماية من مخاطر ذات دوات دوافع اقتصادية.

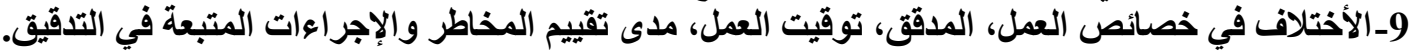

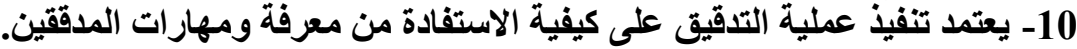

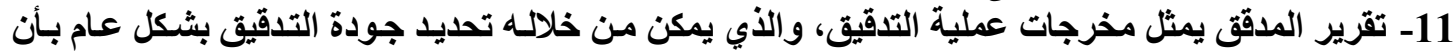

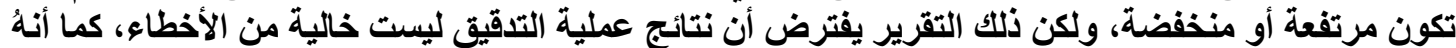

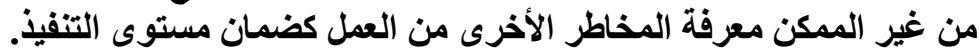

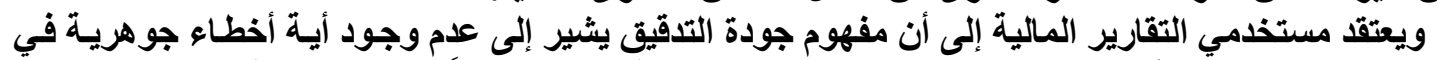

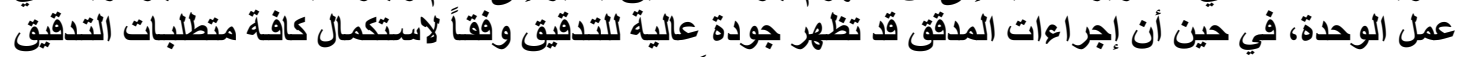

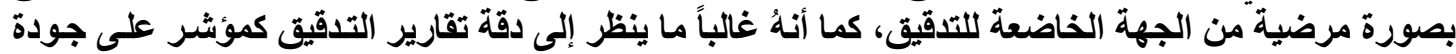

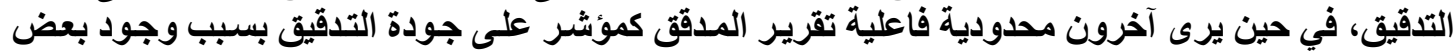

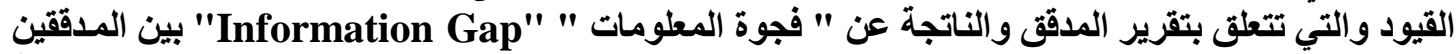

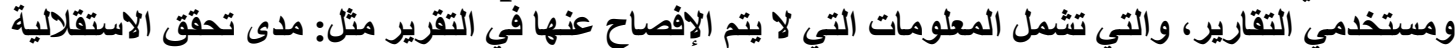

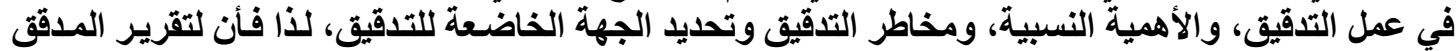

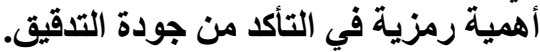
12- كما تعتمد جودة التدقيق على رأي المدقق، والذي قد يتضمن بعض الأخطاء والتي تسمى"فثنل التدقيقي"

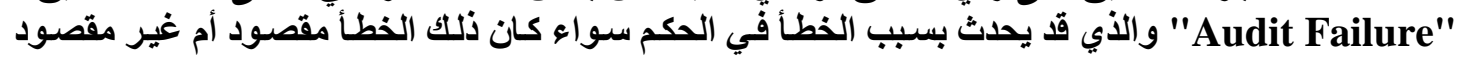

(Knechel et. al., 2012:2-37)

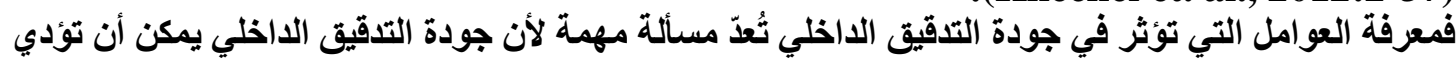

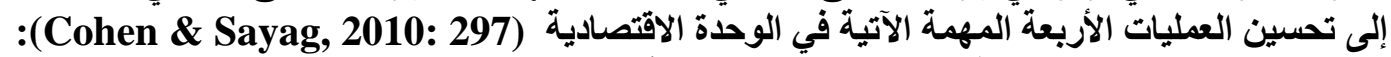

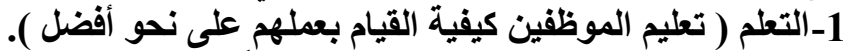

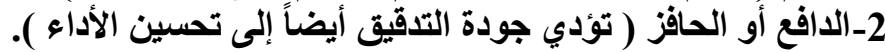

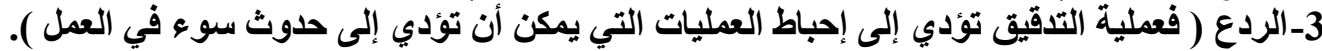
4-تحسين العمليات ( من خلال التأكد من أن العمليات المطلوبة تلتم بالطريقة الصحيحة ) . 


\section{تأثير خبرة المدققا على جورة التدقيقا الداخليا}

وفي المقابل فأن هنالك بعض العوامل التي قد تؤدي إلى عدم تحقق أو انخفاض جودة التدقيق الداخلي

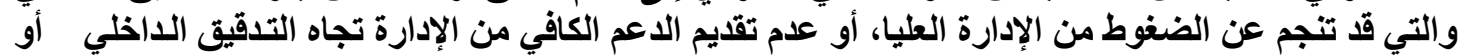
بسبب الضوابط الإدارية غير الفعالة، مما يمكن أن يؤدي إلى (Badara \& Saidin, 2013: 342) 1 1 2-احتمال ظهور الفش والاحتيال.

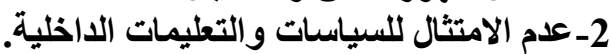
3-الصعوبة في السيطرة على العمليات المالية.

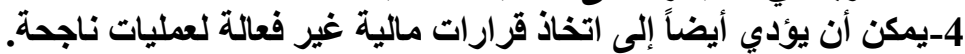

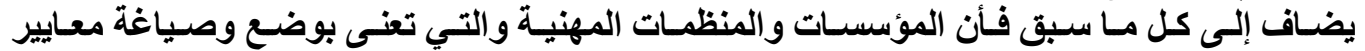
المحاسبة والتّقيق تؤثر بدور ها على جودة التدقيق (Elshafie \& Nyodrah: 2014: 43).

2-2 الرقابة على جودة عملية التدقيقي:

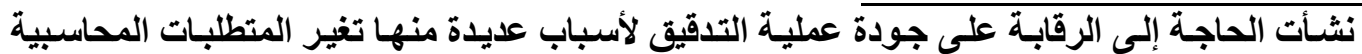

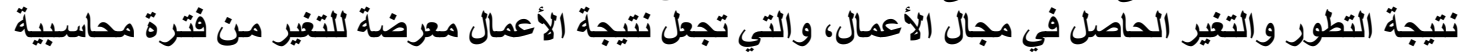

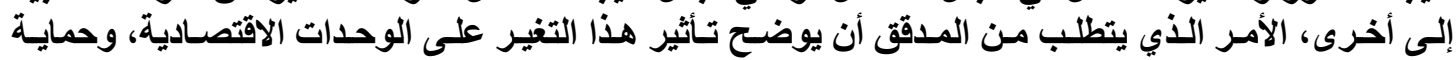

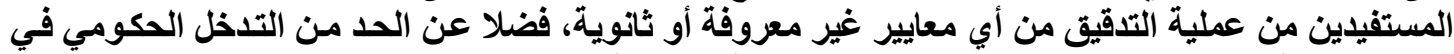

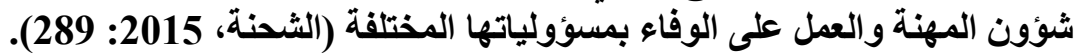

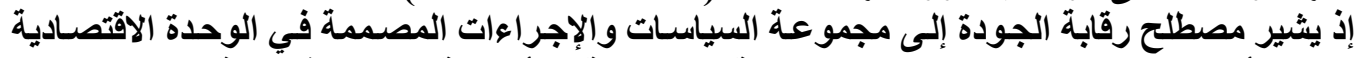

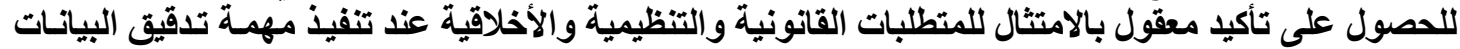

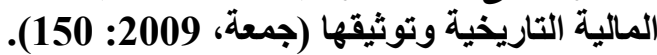

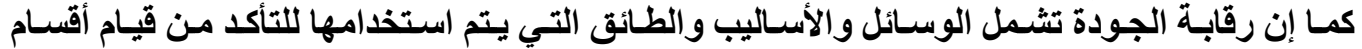

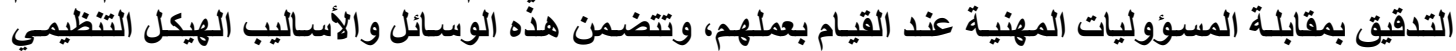

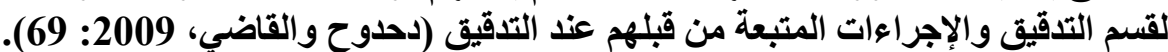

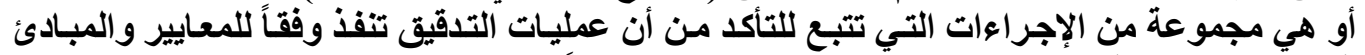

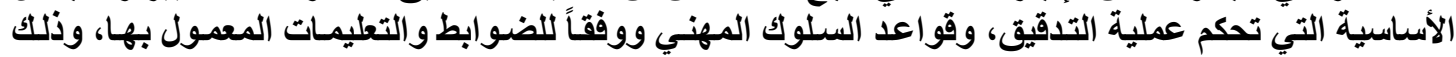

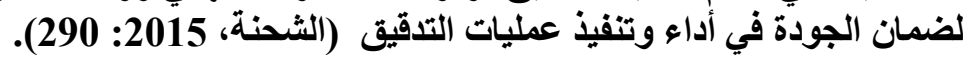

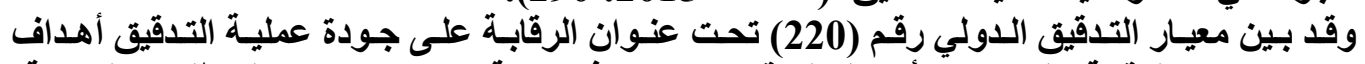

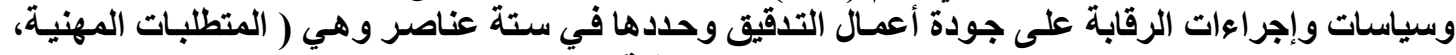

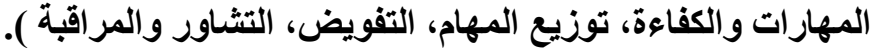

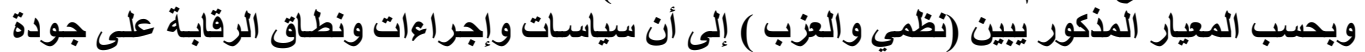

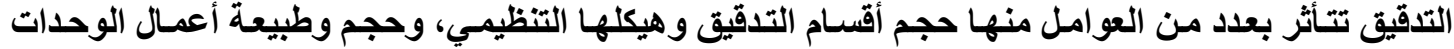

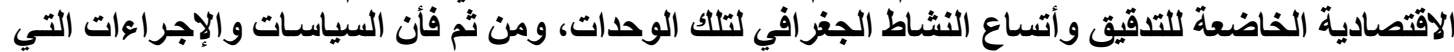

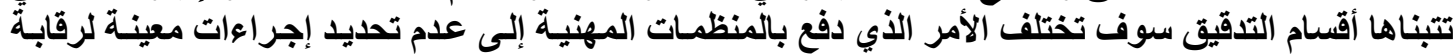
الجودة في أقسام التدقيق (نظمي والعزب، 2012: 185). 


\section{تأثير خبرة المدقق على جورة التدقيقا الداخليا}

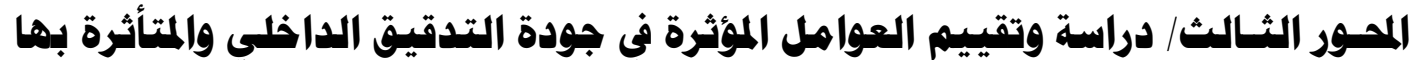

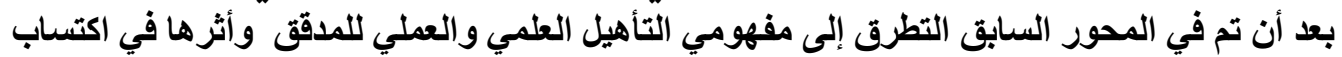

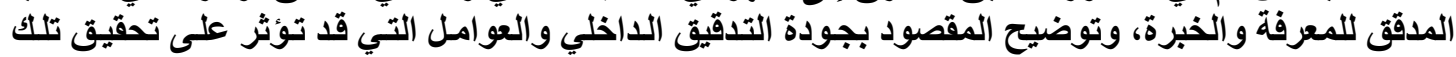

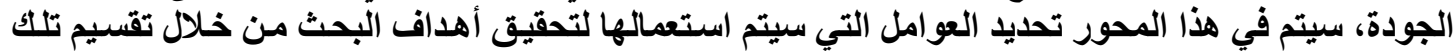

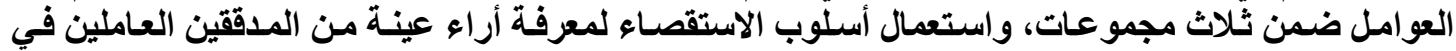

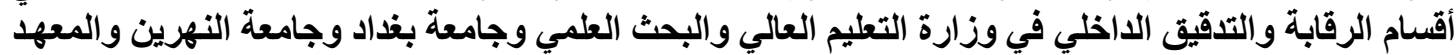
العالي للار اسات المالية و المحاسبية.

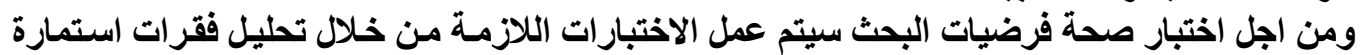

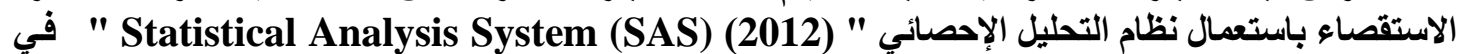

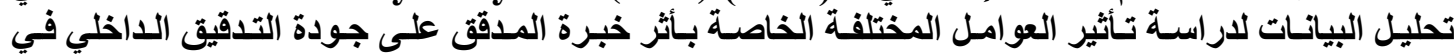

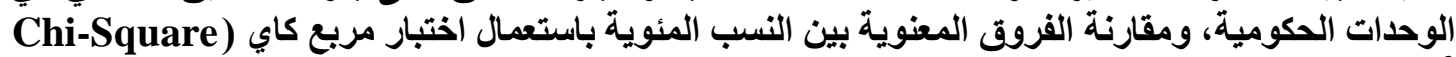

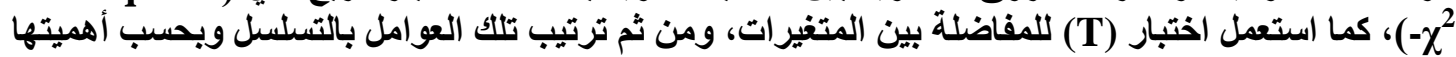

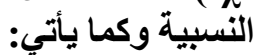

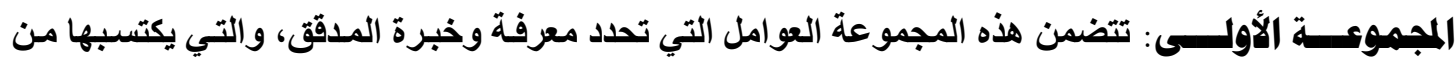

الار اسة الأكاديمية والممارسة المهنية وتضمنت (10) عو امل والتي تؤثر على جودة التدقيق الإخلي وهي:

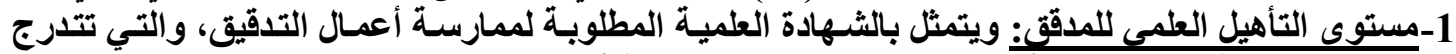

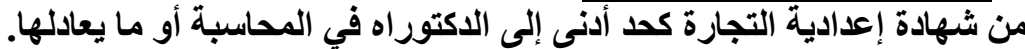

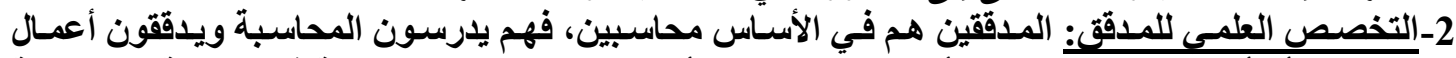

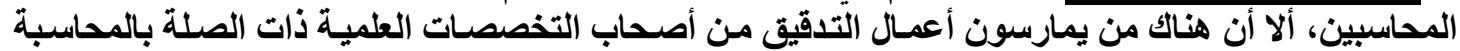

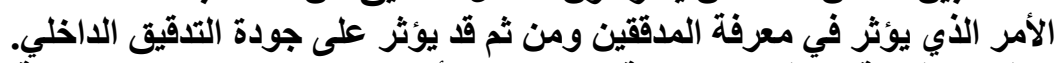

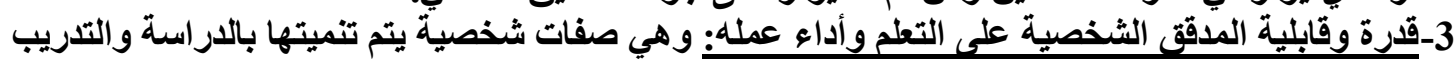

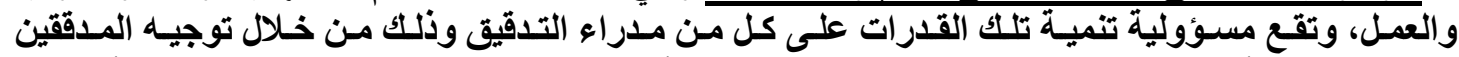
وإطلاعهم على أخر المستجدات في العمل، وعلى المدققين أنفسـهم من خلاعل التعلم والاستفسـار من أصحاب تلفي

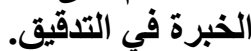

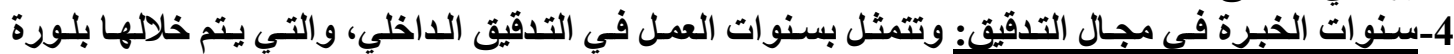

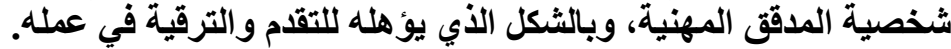

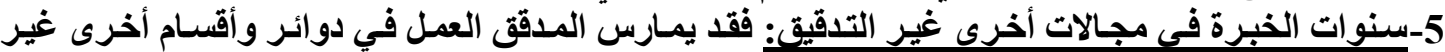

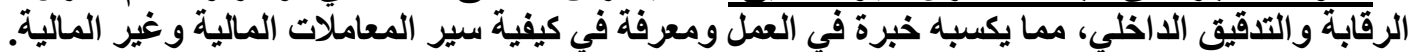

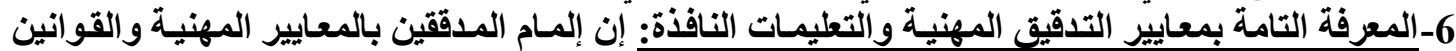

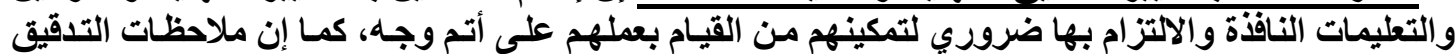

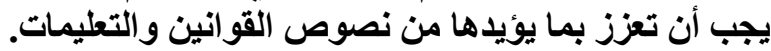

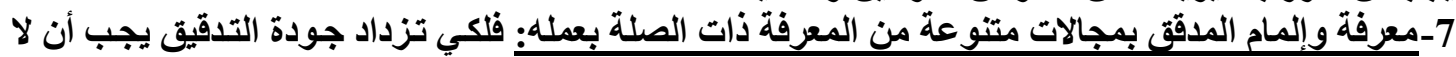

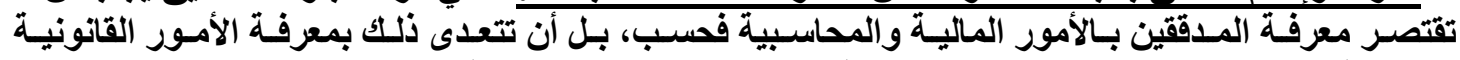
والإدارية وسياقات العمل في الوحدة الاقتصادية، والاستفادة من تلك المعرفة عند التدقيق وبالثكل التهل الذي يعزز من جودة التدقيق الألخي.

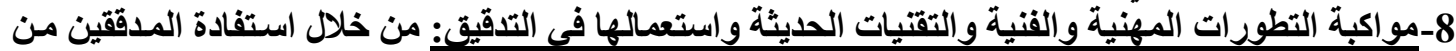

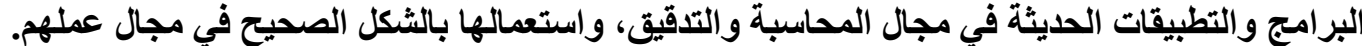

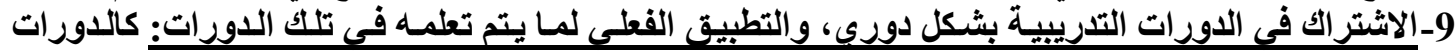

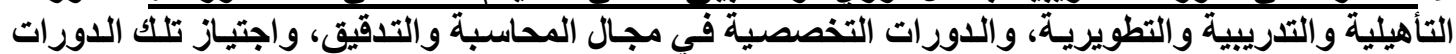

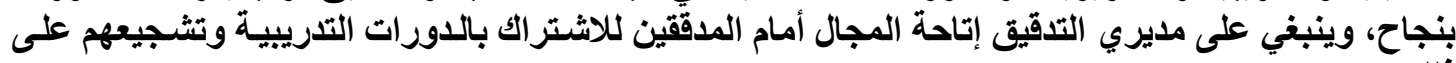




\section{تأثير خبرة المدققا ملى جودة التدقيقا الداخليا}

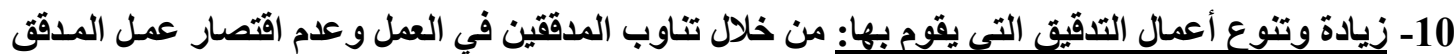

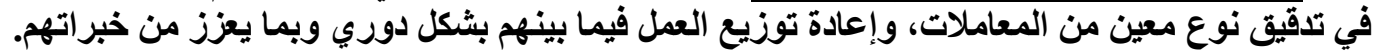

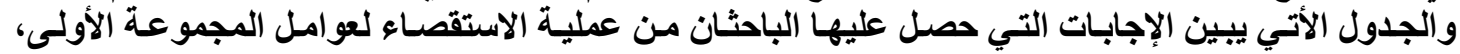
ونتائج التحليل الإحصائي لتلك الإجابات:

الجدول ( 2 ( )

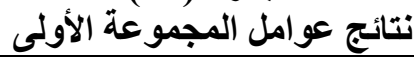

\begin{tabular}{|c|c|c|c|c|c|c|}
\hline الرتبة & الوزن & $\chi^{2}$ & ע & ن نعم & الأسئلة & $ت$ \\
\hline 1 & 25.67 & $* * 14.78$ & $\begin{array}{c}3 \\
(\% 7.5)\end{array}$ & $\begin{array}{c}37 \\
(\% 92.5)\end{array}$ & 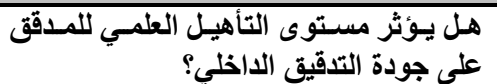 & 1 \\
\hline 2 & 25.33 & $* * 14.07$ & $\begin{array}{c}4 \\
(\% 10.0)\end{array}$ & $\begin{array}{c}36 \\
(\% 90.0)\end{array}$ & 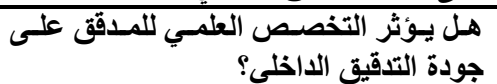 & 2 \\
\hline 1 & 25.67 & $* * 14.78$ & $\begin{array}{c}3 \\
(\% 7.5)\end{array}$ & $\begin{array}{c}37 \\
(\% 92.5)\end{array}$ & 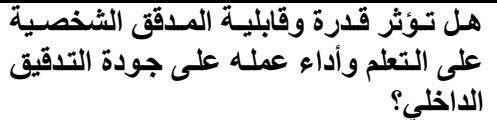 & 3 \\
\hline 2 & 25.33 & $* * 14.07$ & $\begin{array}{c}4 \\
(\% 10.0)\end{array}$ & $\begin{array}{c}36 \\
(\% 90.0)\end{array}$ & 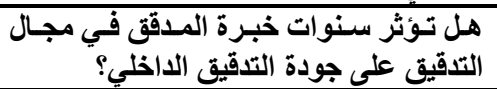 & 4 \\
\hline 6 & 21.33 & $* 7.25$ & $\begin{array}{c}16 \\
(\% 40.0)\end{array}$ & $\begin{array}{c}24 \\
(\% 60.0)\end{array}$ & 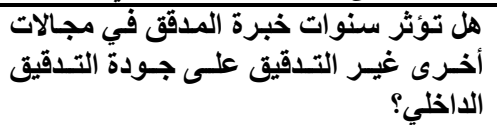 & 5 \\
\hline 1 & 25.67 & $* * 14.78$ & $\begin{array}{c}3 \\
(\% 7.5)\end{array}$ & $\begin{array}{c}37 \\
(\% 92.5)\end{array}$ & 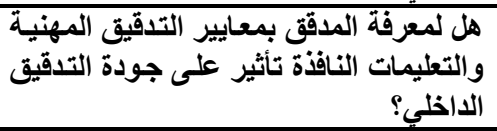 & 6 \\
\hline 3 & 25.00 & $* * 13.89$ & $\begin{array}{c}5 \\
(\% 12.5)\end{array}$ & $\begin{array}{c}35 \\
(\% 87.5)\end{array}$ & 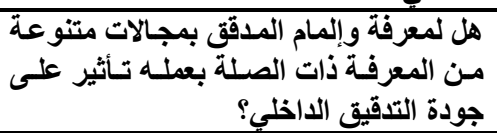 & 7 \\
\hline 1 & 25.67 & $* * 14.78$ & $\begin{array}{c}3 \\
(\% 7.50)\end{array}$ & $\begin{array}{c}37 \\
(\% 92.5)\end{array}$ & 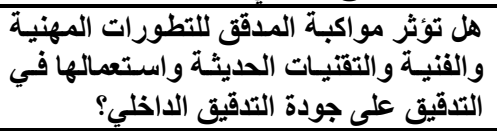 & 8 \\
\hline 5 & 24.00 & $* 7.25$ & $\begin{array}{c}8 \\
(\% 20.0)\end{array}$ & $\begin{array}{c}32 \\
(\% 80.0)\end{array}$ & 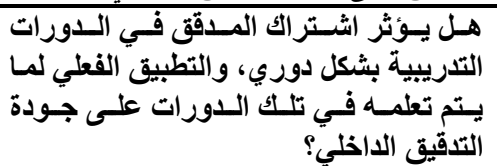 & 9 \\
\hline 4 & 24.33 & $* * 13.47$ & $\begin{array}{c}7 \\
(\% 17.5)\end{array}$ & $\begin{array}{c}33 \\
(\% 82.5)\end{array}$ & 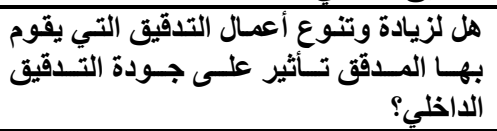 & 10 \\
\hline --- & $* 1.63$ & --- & --- & --- & قيمة T-Test & \\
\hline
\end{tabular}

. $(\mathbf{P}<0.01) * * ،(\mathbf{P}<0.05)$ *

من خلال دراسة وتحليل الإجابات الواردة في الجدول المذكور آنفاً فقد أظهرت نتائج اختبار مربع كاي

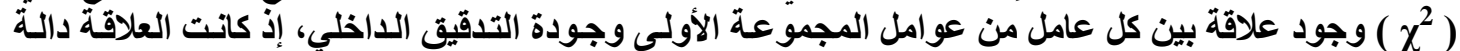

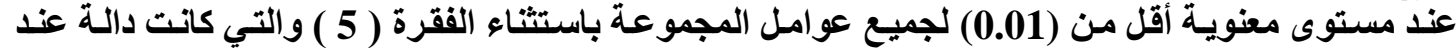
مستوى معنوية أقل (0.05).

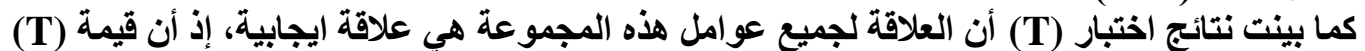
المحسوبة للمجموعة ككل دالة عند مستوى معنوية أقلّ من (1) (0.05).

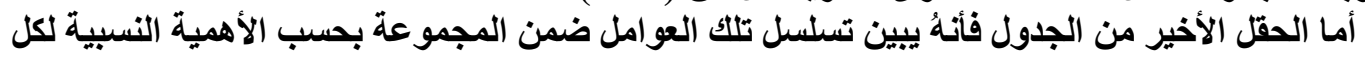
عامل في ضوء أراء المستجيبين. 


\section{تأثير خبرة المدقق على جورة التدقيقا الداخليا}

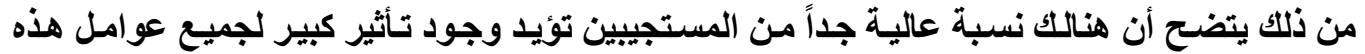

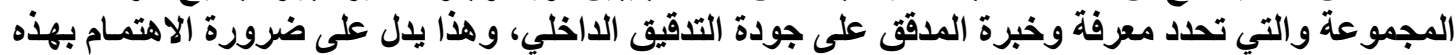

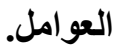

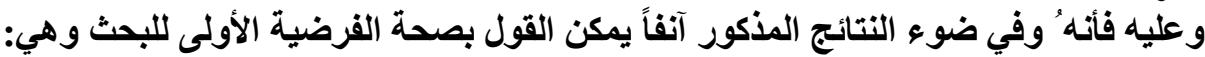

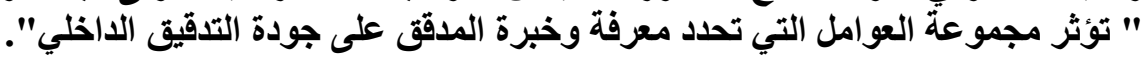

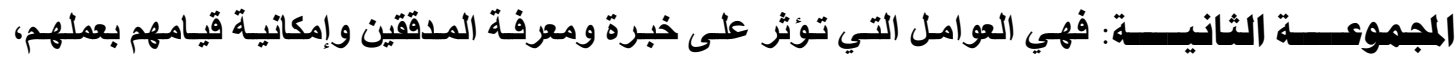

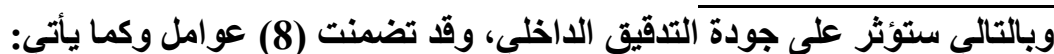

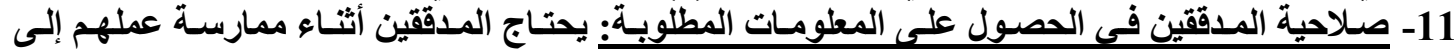

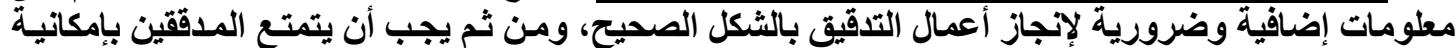

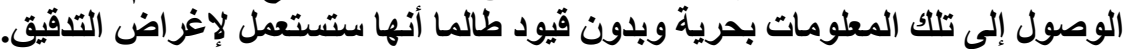

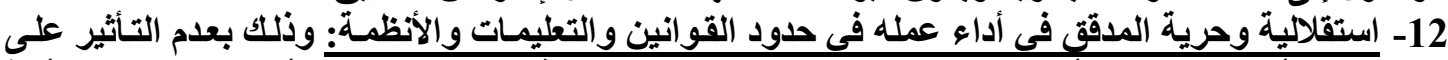

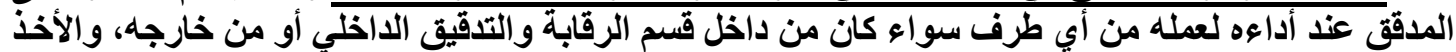

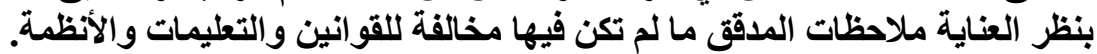

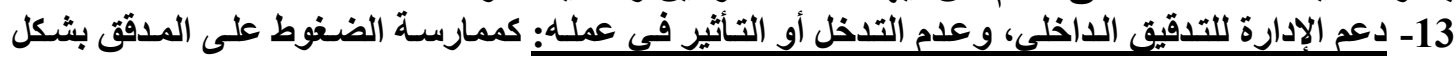

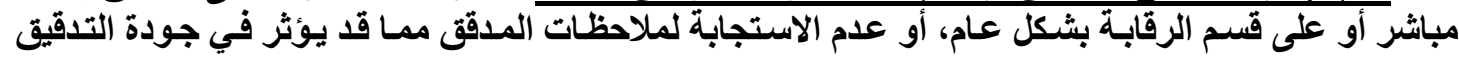
الاخلي. 14- تخصص المدققين في تدقيق قطاع معين من الأعمال: وذلك من خلال تدقيق المعاملات الخاصة بقطاع أو

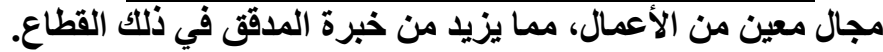

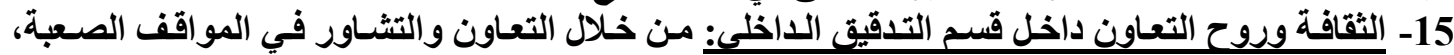

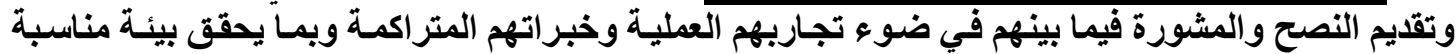
للعقل.

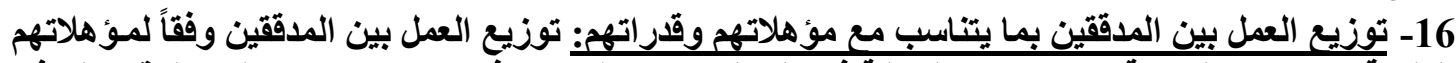

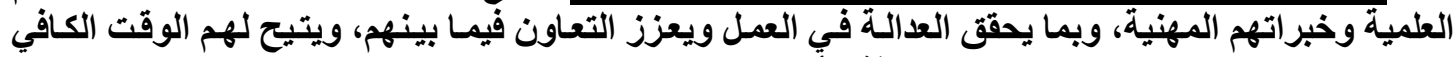

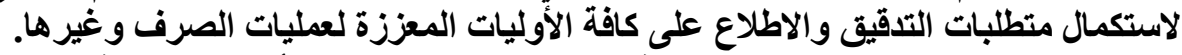

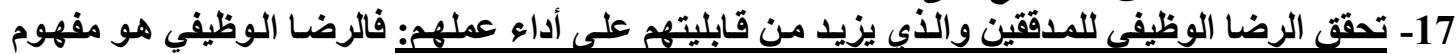

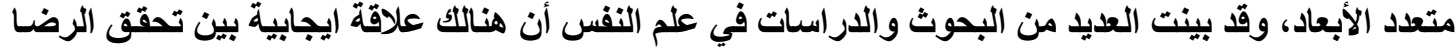
الوظيفي للموظفين وبين أداؤهم لعملهم.

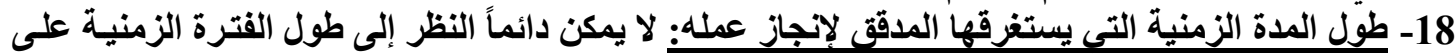

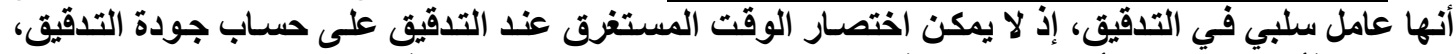

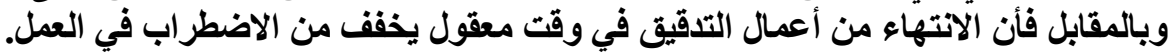

والجدول الأتي يبين الإجابـات التي حصل عليها الباحثان من عملية الاستقصـاء لعوامل المجموعة الثانيـة، ونتائج التحليل الإحصائي لتلتك الإجابات: 


\section{تأثير خبرة المدقق ملى جودة التدقيقا الداخليا}

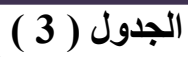

نتائج عوامل المجموعة الثانية

\begin{tabular}{|c|c|c|c|c|c|c|}
\hline 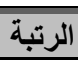 & 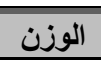 & $\chi^{2}$ & ע & 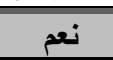 & الأسئلة & $ت$ \\
\hline 1 & 25.33 & $* * 14.07$ & $\begin{array}{c}4 \\
(\% 10)\end{array}$ & $\begin{array}{c}36 \\
(\% 90)\end{array}$ & 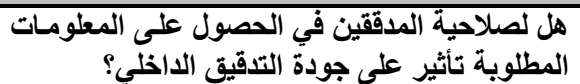 & 11 \\
\hline 1 & 25.33 & $* * 14.07$ & $\begin{array}{c}4 \\
(\% 10)\end{array}$ & $\begin{array}{c}36 \\
(\% 90)\end{array}$ & 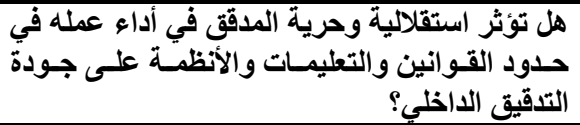 & 12 \\
\hline 2 & 24.67 & $* * 13.49$ & $\begin{array}{c}6 \\
(\% 15)\end{array}$ & $\begin{array}{c}34 \\
(\% 85)\end{array}$ & 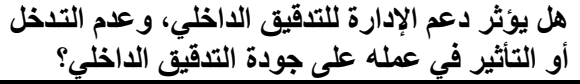 & 13 \\
\hline 4 & 23.33 & $* * 12.63$ & $\begin{array}{c}10 \\
(\% 25)\end{array}$ & $\begin{array}{c}30 \\
(\% 75)\end{array}$ & هن الأعمال على تخص جودة التدقيق في الداخلي؟ قدقيق قطاع معين & 14 \\
\hline 5 & 22.67 & $* * 12.05$ & $\begin{array}{c}12 \\
(\% 30) \\
\end{array}$ & $\begin{array}{c}28 \\
(\% 70) \\
\end{array}$ & 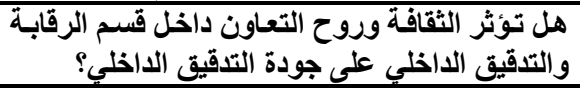 & 15 \\
\hline 3 & 24.00 & $* * 7.25$ & $\begin{array}{c}8 \\
(\% 20)\end{array}$ & $\begin{array}{c}32 \\
(\% 80)\end{array}$ & 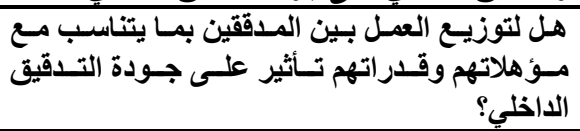 & 16 \\
\hline 2 & 24.67 & $* * 13.73$ & $\begin{array}{c}6 \\
(\% 15)\end{array}$ & $\begin{array}{c}34 \\
(\% 85)\end{array}$ & 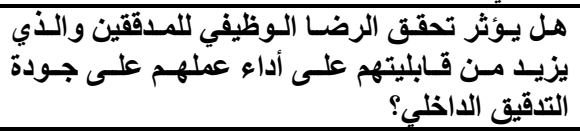 & 17 \\
\hline 6 & 22.00 & $* * 9.26$ & $\begin{array}{c}14 \\
(\% 35) \\
\end{array}$ & $\begin{array}{c}26 \\
(\% 65) \\
\end{array}$ & 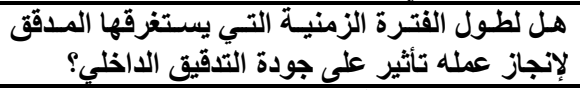 & 18 \\
\hline--- & $* 1.35$ & -- & --- & --- & T-Test قيمة & \\
\hline
\end{tabular}

.$(\mathbf{P}<0.01) * *$ * $(\mathbf{P}<0.05) *$

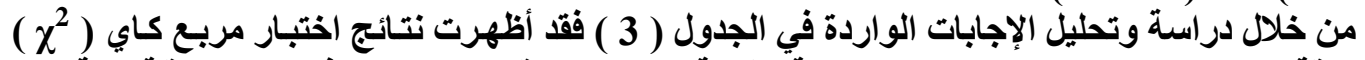

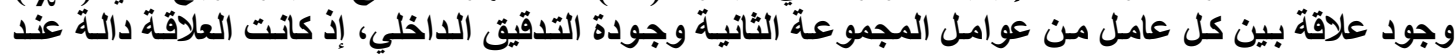

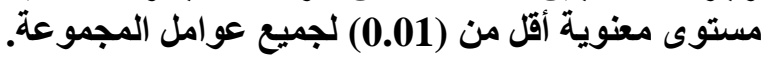

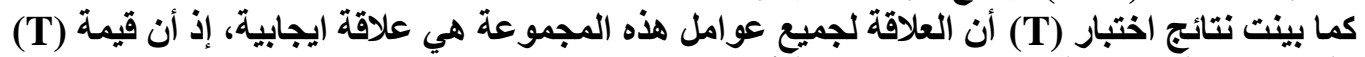

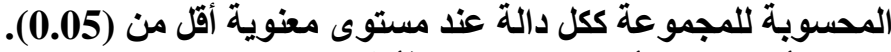

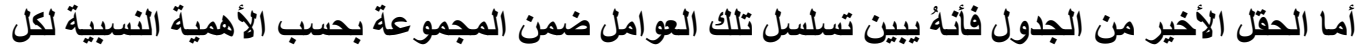
عامل في ضوء أراء المستجيبين.

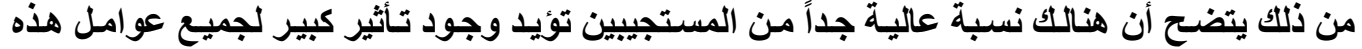

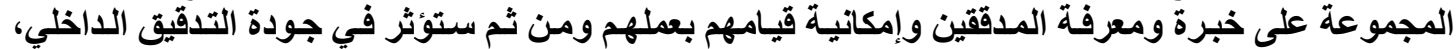

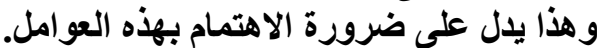

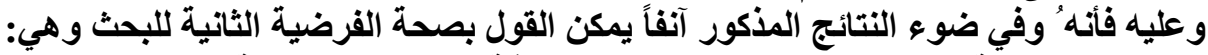

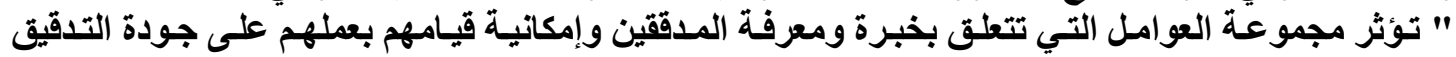
الاخلي ".

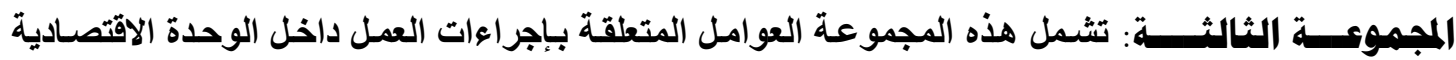

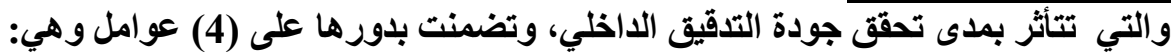

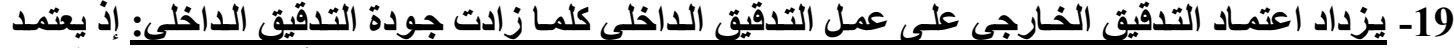

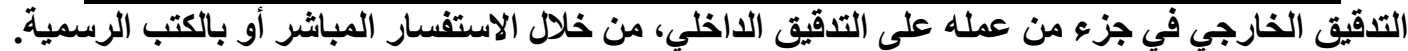

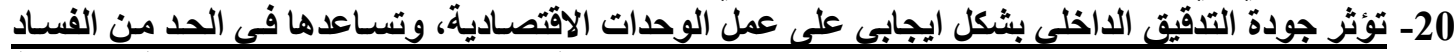

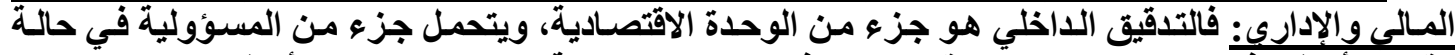

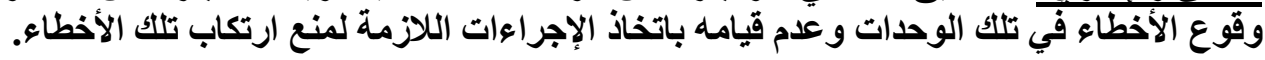




\section{تأثير خبرة المدققا ملى جودة التدقيقا الداخليا}

21- زيادة الجودة في عمل التدقيق الداخلى تضمن التز ام كافة الموظفين بالقو انين والأنظمة والتعليمـات، وأداء

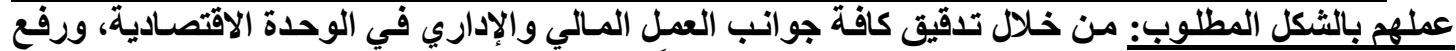

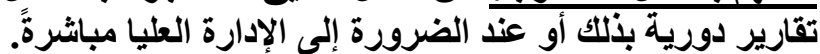

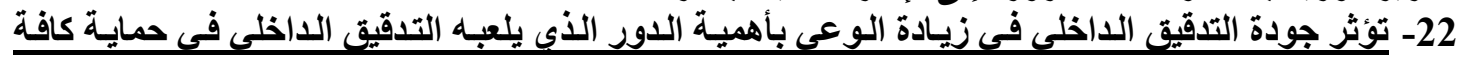

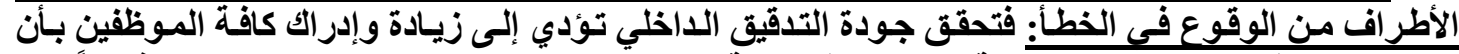

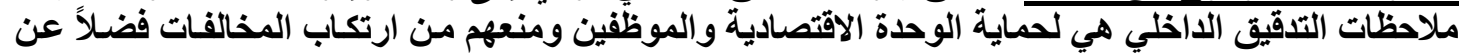

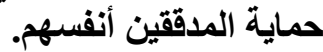
والجدول الأتي يبين الإجابـات التي حصل عليها الباحثنان من عملية الاستقصـاء لعوامل المجموعة الثالثة، ونتائج التحليل الإحصائي لتبك الإجابات:

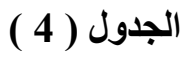

نتائج عوامل المجموعة (الثالثة

\begin{tabular}{|c|c|c|c|c|c|c|}
\hline الرتبة & الوزن - م الون & $\chi^{2}$ & ע & نعم & الأسئلة & $ت$ \\
\hline 3 & 24.00 & $* * 7.25$ & $\begin{array}{c}8 \\
(\% 20.0)\end{array}$ & $\begin{array}{c}32 \\
(\% 80.0)\end{array}$ & 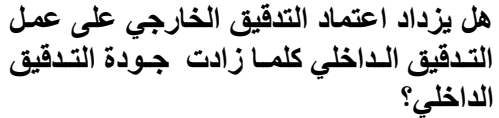 & 19 \\
\hline 1 & 25.67 & $* * 14.78$ & $\begin{array}{c}3 \\
(\% 7.5)\end{array}$ & $\begin{array}{c}37 \\
(\% 92.5)\end{array}$ & 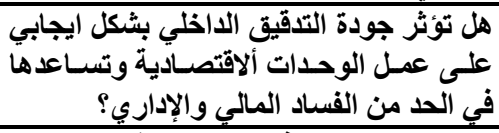 & 20 \\
\hline 2 & 24.33 & $* * 13.29$ & $\begin{array}{c}7 \\
(\% 17.5)\end{array}$ & $\begin{array}{c}33 \\
(\% 82.5)\end{array}$ & 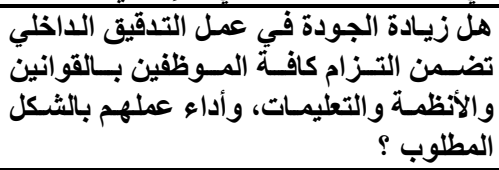 & 21 \\
\hline 2 & 24.33 & $* * 13.29$ & $\begin{array}{c}7 \\
(\% 17.5)\end{array}$ & $\begin{array}{c}33 \\
(\% 82.5)\end{array}$ & 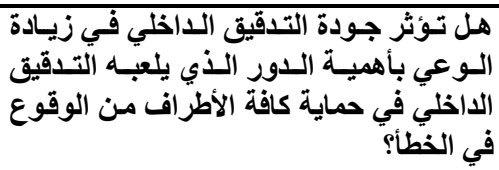 & 22 \\
\hline--- & $* 1.09$ & --- & --- & --- & قيمة & \\
\hline
\end{tabular}

من خلال دراسة وتحليل الإجابات الواردة في الجدول( 4 ) فقد أظهرت نتائج اختبار مربع كاي (

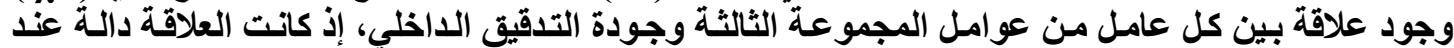

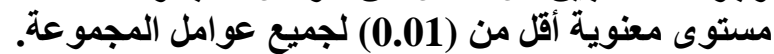

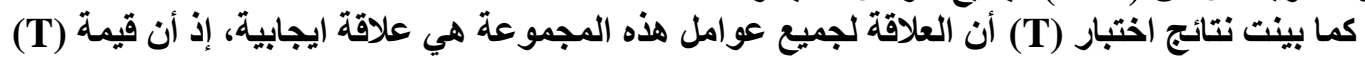

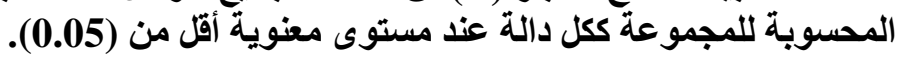

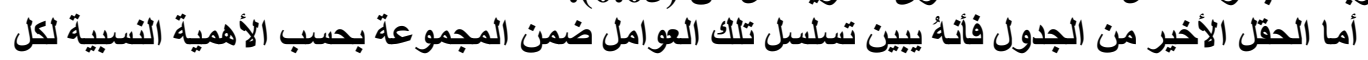
عامل في ضوء أراء المستجيبين. من ذلك يتضح أن هنالكك نسبة عالية جداً من المستجيبين تؤيدا وجود تأثير كبير لجودة التدقيق الداخلي

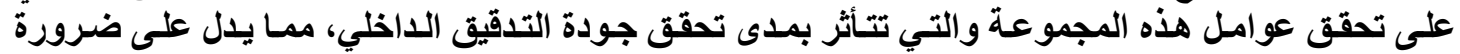

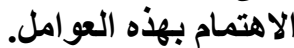
وعليه فأنهُ وفي ضؤهو التوائه التتائج المذكور آنفاً يمكن القول بصحة الفرضية الثالثة للبحث وهي: " تتأثر إجراءات العمل داخل الوحدة الاقتصادية بمدى تحقى جودة التدقيق الداخلي ". 


\section{تأثير خبرة المدقق على جودة التوقيقا الداخليا}

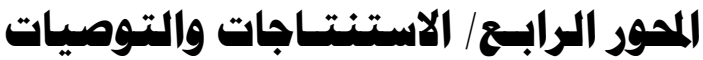 \\ يمثل هذا المحور خلاصة ما تم التوصل إليه من استنتاجات فضلاءعن توضيح أهم التوصيات:}

أولا: الاستنتاجات:

من الاستنتاجات التي تم التوصل إليها البحث وعلى الإنى المستويين النظري والعملي هي:

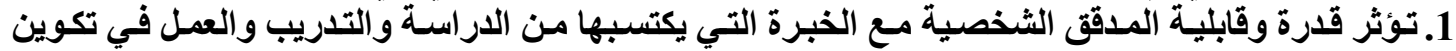

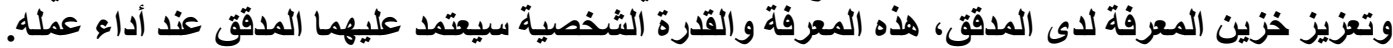

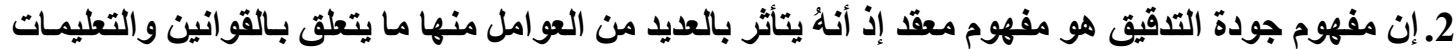

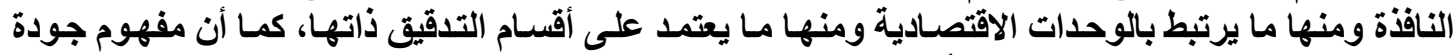

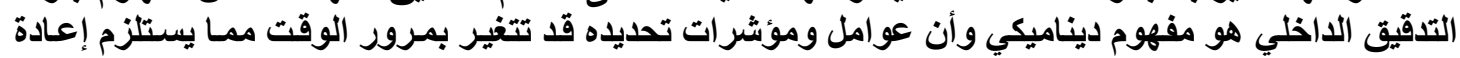
النظر في تلك التعوامل والمؤشر مفردات.

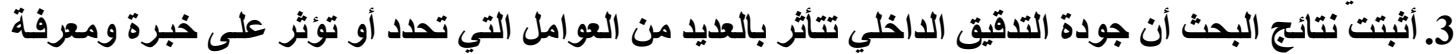

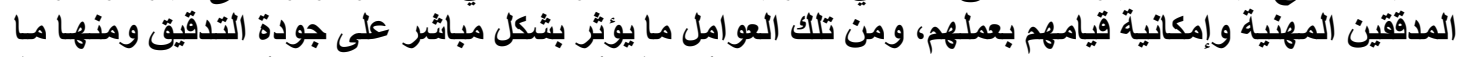

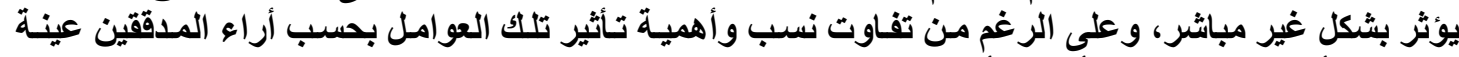

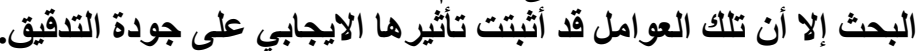

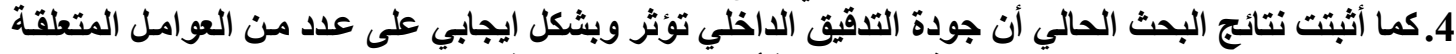

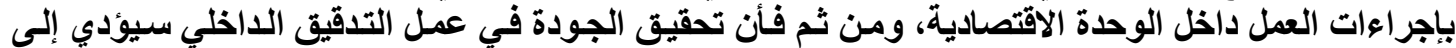
تسهيل وتحسين العمل في الوحدات الودة الاقتصادية.

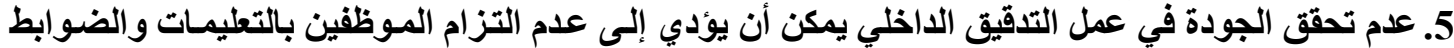

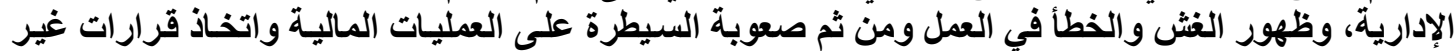

\section{ثانيبا: التوصيات:

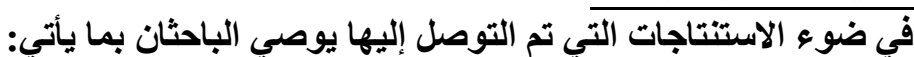

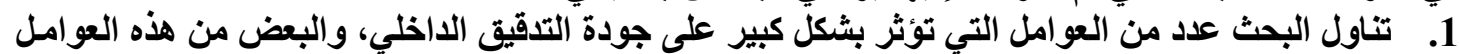

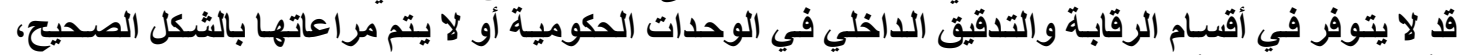

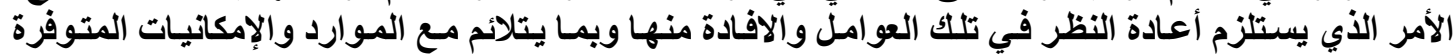
لتحقيق وتعزيز الجودة في عمل تلكت الأقسام.

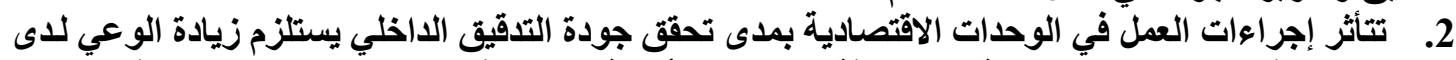

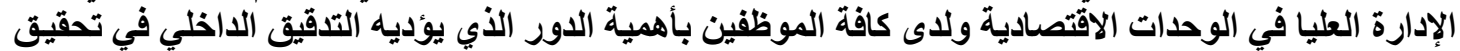

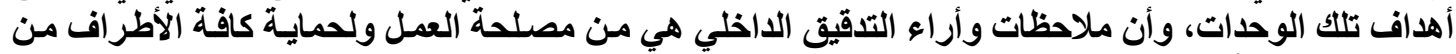
الوقوع في الخطأ.

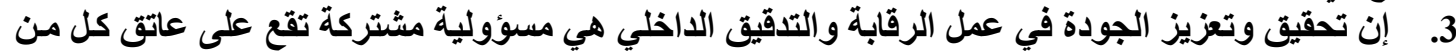

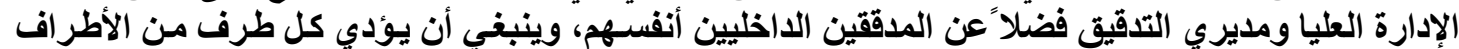

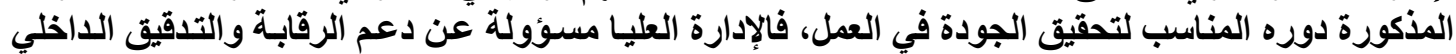

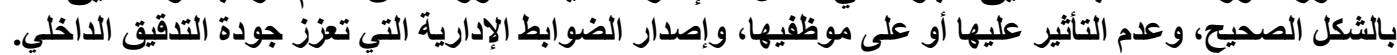

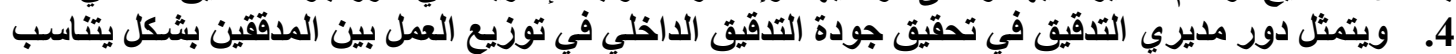

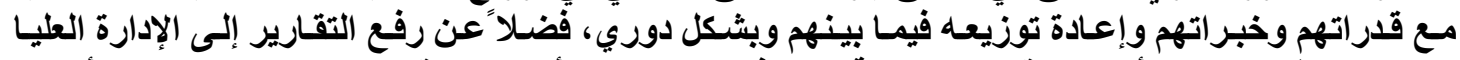

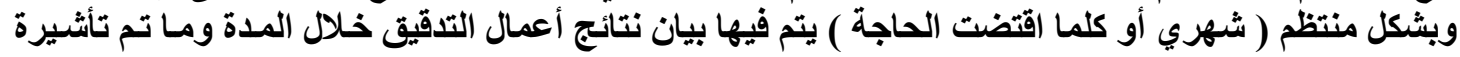

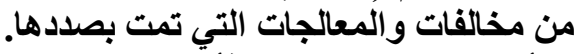

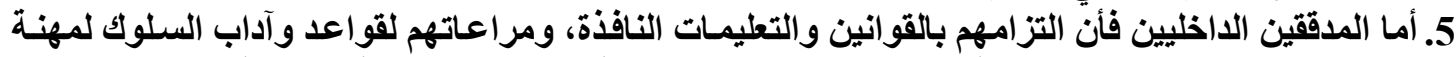

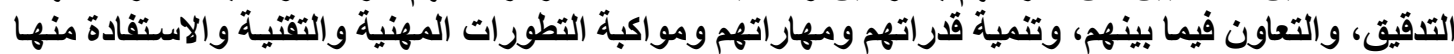
في التّقيق يعد اكبر عامل لتحقيق الجودة في عملهم. 


\section{تأثير خبرة المدقق ملى جودة التدقيقا الداخليا}

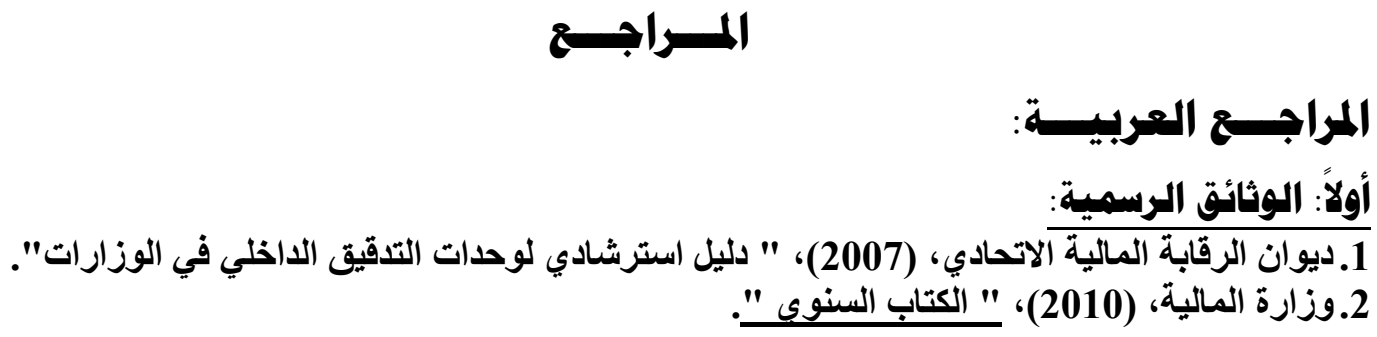

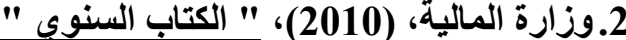

1. جمعة، احمد حلمي، (2009)، " المدخل إلى التدقيق والتأكيد الحديث "، الطبعة الأولى، دار صفاء للنشر

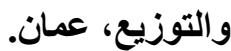

2. جمعة، احمد حلمي، (2011)، " التدقيق والتأكيد المتقدم "، الطبعة الأولى، دار صفاء للنشر والتوزيع،

3. دحدوح، حسين أحمد والقاضي، حسين يوسف، (2009)، " مراجعة الحسـابات المتقدمة، الإطسار النظري

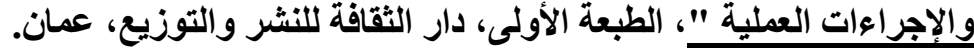

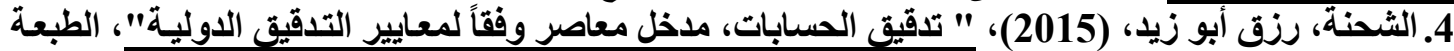
الأولى، دار وائل للنشر والتوزئ زلتوزيع، عمان. 5. نظمي، إيهاب والعزب، هاني، (2012)، " تدقيق الحسـابات، الإطار النظري "، الطبعة الأولى، دار وائل

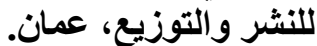

ثالثا: البحوث والدراسات والدوريات:

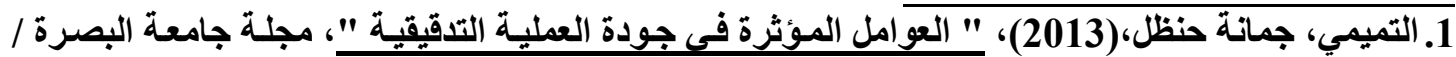
كلية الإدارة والاقتصاد، المجلد الخامس، العدد العاشر.

\section{Foreign References}

\section{First: Thesis:-}

1. Aamir, Suhaib \& Farooq, Umar, (2011), " Auditor client relationship and audit Quality ", Master Thesis, the Umea School of Business at Umea University, Sweden.

2. Abdullah, Razimah, (2014), " Redefining Internal Audit Performance: Impact on Corporate Governance ", Doctor of Philosophy Thesis, Edith Cowan University, School of Business, Faculty of Business and Law, Western Australia

3. Berberich, Gregory Paul, (2005), "The Effects of Audit Methodology and Audit Experience on the Development of Auditors' Knowledge of the Client's Business ", Doctor of Philosophy In Accounting Thesis, University of Waterloo, Ontario, Canada.

4. Sulaiman, Noor Adwa, (2011), "Audit Quality in Practice: A Study of Perceptions of Auditors, Audit Committee Members and Quality Inspectors ", Doctor of Philosophy Thesis, Manchester Business School, the University of Manchester, U.K.

5. Trotman, Andrew J., (2013), "Internal Audit Quality: A Multi-Stakeholder Analysis ", Doctor of Philosophy Thesis, School of Business, Bond University, Australia. 


\section{تأثير خبرة المدقق على جورة التدقيقا الداخليا}

\section{Second: Periodicals \& Reports:-}

1. Badara, Mu'azu Saidu \& Saidin, Siti Zabedah, (2013), " The Journey so far on Internal Audit Effectiveness: A Calling for Expansion ", International Journal of Academic Research in Accounting, Finance and Management Sciences Vol.( 3), No.(3), pp.(340-351).

2. Behn, Bruce K. \& et. al., (2008), "Audit Quality and Properties of Analyst Earnings Forecasts ", The Accounting Review, Vol. (83), No.(2), pp.(327-349).

3. Bonner, Sarah E. \& Lewis, Barry L., (1990), " Determinants of Auditor Expertise ", Journal of Accounting Research, Vol.( 28), pp.(1-20).

4. Bouhawia, Mohammed.S., \& et. al., (2015), " The Effect of Working Experience, Integrity, Competence, and Organizational Commitment on Audit Quality (Survey State Owned Companies In Libya ", IOSR Journal of Economics and Finance, e-SSN: (23215933), p-ISSN:(2321-5925).Vol.(6), Issue(4), pp:(60-67).

5. Cohen, Aaron \& Sayag, Gabriel, (2010), " The Effectiveness of Internal Auditing ", Australian Accounting Review, No.(54), Vol.(20), Issue(3), pp.(296-307).

6. Curtis, Mary B. \& et. al., (2009), "Auditors' Training and Proficiency in Information Systems: A Research Synthesis ", Journal of Information Systems, Vol.(23), No.(1), pp. (79-96).

7. Elshafie, Essam \& Nyadroh, Emmanuel, (2014), "Are Discretionary Accruals a Good Measure of Audit Quality?", Journal of Management Policy and Practice, Vol. 15(2), pp:(43-59).

8. Financial Reporting Council (FRC), (2008), "The Audit Quality Framework".

9. Knechel, W. Robert, (2013), " Do Auditing Standards Matter?", American Accounting Association, Vol.( 7), Issue( 2), pp.(15-23).

10.Ohiokha, Friday Izien \& Akhalumeh, Paul Benign, (2013), "Auditing Standards \& Auditors Performance: the Nigerian Experience", European Journal of Accounting Auditing and Finance Research, Vol.(1), No.(3), pp.(15-23).

11. Sakour, Abdelwahab Sassi \& Laila, Nur Hidayah Binti, (2015), "Internal Audit Effectiveness in Libyan Public Enterprises: An Approach to the Development of a Theoretical Framework ", Global Business and Management Research: An International Journal Vol.(7), No.(2), p.p.(12-18).

Third: Resources From Internet:-

1. Benslimene, Imen \& Dumontier, Pascal, (2014), " The Complementary Impacts of Audit Regulation and Auditor Quality on Earnings Quality: The European Evidence ", Available online at:

http://wp.unil.ch/earnet2015/files/2014/10/The-complementary-Impacts-of-Audit-

Regulation-and-Auditor-Quality-on-Earnings-Quality-the-European-Evidence.pdf

2. Bonnes, Bas, ( 2012), " Internal Audit ", Available online at:

dare.uva.nl/document/476940

3. GAAS, Generally Accepted Auditing Standards," Auditing Standards, General Standards", (2001), Available online at:

http://www.aicpa.org/Research/Standards/AuditAttest/DownloadableDocuments/AU00150.pdlf.

4. Knechel, W. Robert \& et. al., (2012), "Audit Quality: Insights from the Academic Literature ", Available online at: http://ssrn.com/abstrcat=2040754 


\section{تأثير خبرة المدقق ملى جودة التدقيقا الداخليا}

\section{" The Effect of the Auditor's Experience on the Quality of Internal Audit " Abstract:}

The importance of internal audit in the growing demand for services in the public and private economic units, and in the rapid growth of its systems professional, has also been recognition of the importance of internal audit quality and the quality of information provided in a long time, as well as the importance of achieving the greatest possible quality in his work to reduce accounting risks of financial reports misleading or fraudulent, which is one of the important features of the audit.

The internal audit quality are linked with the ability of auditors to detect errors in the financial statements, and their willingness to express an opinion technical neutral and non-aligned based on the results of the audit process, improve efficiency and organizational effectiveness of economic units through the constructive criticism, and in fact the internal audit has become an indispensable tool for achieving effective control in economic units.

Also internal audit quality will increase the adoption of external audit on the work of the internal audit, which increases the efficiency of the external audit and reduce its burden.

As the experience in the work ensures achievement of the objectives, the internal audit experience plays an important role in ensuring achievement of its economic units objectives and objectively.

In this research will be to examine the impact of Internal Auditors experience of scientific and practical point of view on the quality of internal audit work, depending on the survey method through knowledge of the opinions of a sample of auditors working in the departments of control and internal audit in the Ministry of Higher Education and Scientific Research, and the University of Baghdad and Nahrain University and the Post Graduate Institute for Accounting \& Financial Studies, and analysis data using the statistical analysis system (SAS).

Key words: Auditor, Auditor Experience, Internal Audit, Internal Audit Quality. 